\title{
Synthesis and Evaluation of 1,2,3-Triazole-Containing Vinyl and Allyl Sulfones as Anti-Trypanosomal Agents
}

\author{
William Doherty, ${ }^{[a]}$ Nikoletta Adler ${ }^{[b]}$ Andrew Knox, ${ }^{[b, c]}$ Derek Nolan, ${ }^{[b]}$ Joanna McGouran, ${ }^{[d]}$ Anna \\ Pratima Nikalje, ${ }^{[\mathrm{e}]}$ Aniket Sarkate,${ }^{[\mathrm{ff}}$ Deepak Lokwani, ${ }^{[\mathrm{ff}]}$ and Paul Evans ${ }^{*[a]}$
}

\begin{abstract}
An approach is described to access 1,2,3-triazole-derived peptidyl vinyl sulfone Trypanosoma brucei brucei inhibitors via click chemistry, from a common azide intermediate. Among the triazole analogues, biotinylated inhibitors $\mathbf{1 1}$ and $\mathbf{1 2}$ offer possibilities as probes for the elucidation of the target proteases for this compound class. The development of two syntheses of a 1,2,3-triazole based vinyl sulfone $\mathbf{5}$ are also presented. This compound was accessed through a click reaction of a lysine-derived azide (itself accessed via diazotransfer), and a phenylalanine-derived alkyne synthesized by both Ohira-Bestmann and Corey-Fuchs-based alkynylation protocols. Several members of this family of compounds demonstrated promising anti-trypanosomal activity and unexpectedly, amongst the most active compound, was allyl sulfone $\mathbf{2 4}$, which stemming from the isomerization of the vinyl sulfone $\mathbf{5}$, is presumably a reversible inhibitor. A docking study of the analogues was performed in the active site of the parasitic cysteine protease rhodesain in order to gain an insight into their likely interactions with these enzymes.
\end{abstract}

\section{Introduction}

Human African Trypanosomiasis (HAT) is a neglected tropical disease ${ }^{[1]}$ endemic to 36 countries in sub-Saharan Africa. ${ }^{[2]}$ It is spread by the bite of the tsetse fly and is caused by Trypanosoma brucei (kinetoplastid protozoan parasites). $T$. brucei are single cellular, eukaryotic organisms with whip-like organelles or flagella. Once the host is infected, these parasites reside extracellularly in the bloodstream and other bodily fluids, such as cerebrospinal fluid or the lymphatic system. ${ }^{[2]}$ The host then acts as a 'reservoir' for the parasite. There are two forms

[a] W. Doherty, P. Evans.

Centre for Synthesis and Chemical Biology, School of Chemistry, University College Dublin, Dublin 4, Ireland.

E-mail:paul.evans@ucd.ie

[b] N. Adler, A. Knox, D. Nolan.

School of Biochemistry and Immunology, Trinity Biomedica

Sciences Institute, Trinity College Dublin, Pearse Street, Dublin 2, Ireland.

[c] A. Knox.

School of Biological Sciences, Dublin Institute of Technology, Kevin Street, Dublin 8, Ireland.

[d] J. McGouran.

School of Chemistry, Trinity Biomedical Sciences Institute, Trinity College Dublin, Pearse Street, Dublin 2, Ireland.

[e] A. P. Nikalje.

Y. B. Chavan College of Pharmacy, Dr. Rafiq Zakaria Campus, Aurangabad-431001, Maharashtra, India.

[f] A.Sarkate, D.Lokwani.

Department of Chemical Technology, Dr. Babasaheb Ambedkar Marathwada University, Aurangabad-431004, Maharashtra, India.

Supporting information for this article is given via a link at the end of the document. of HAT: T. b. gambiense which is responsible for $98 \%$ of reported cases and $T . b$. rhodesiense (responsible for the remaining $2 \%$ of cases). ${ }^{[2]} \quad T$. $b$. gambiense is prevalent in Central and Western Africa and causes a chronic infection whereas $T . b$. rhodesiense is localized in eastern and southern Africa and causes a rapid acute infection with higher mortality rates when compared to $T$. b. gambiense. ${ }^{[3]}$ It is currently estimated that $\sim 20,000$ people are infected with HAT worldwide. $^{[4]}$ However, the number of new reported cases in 2015 was less than 3000 and in 2016, the World Health Organization reported the positive news that the number of cases of HAT had dropped to its lowest level in 75 years. ${ }^{[5]}$ This decrease in the number of cases has been ascribed to a range of initiatives including vector control (e.g. tsetse fly traps) and host reservoir control. ${ }^{[6]}$ Nevertheless, 65 million people remain at risk from this disease each year ${ }^{[2,4]}$ and a concerted effort is required to eradicate this disease. If left untreated, HAT is ultimately fatal and while a vaccine for this disease would certainly be ideal, this has not been achieved to date due to the variant surface glycoproteins coating the surface of $T$. brucei. ${ }^{[7]}$ This densely packed glycoprotein 'coat' surrounds the parasite and prevents access to the plasma membrane which ensures that the trypanosomes evade effective intervention of the host's immune system. Accordingly, chemotherapy is currently the only option for the treatment of HAT and still relies heavily on treatments developed several years ago. ${ }^{[8]}$ These treatments are not satisfactory due to a combination of parasite resistance, toxicity concerns and difficulties associated with drug administration (e.g. intravenous injection, dose control etc.). Additionally, there is a bovine form of the disease caused by three subspecies of Trypanosoma: $T$. b. brucei, $T$. congolense and $T$. vivax. These parasites cause Nagana, which afflicts livestock, causing an economic and developmental burden on farming communities. ${ }^{[2]}$ Thus, the development of both new human and veterinary treatments would be of great benefit.

In relation to this, peptidyl vinyl sulfones ${ }^{[9,10]}$ are a class of compound possessing promising anti-trypanosomal effects, which, at least in part, can be explained on the basis of their interaction with vital trypanosomal cysteine proteases. ${ }^{[11,12,13]}$ Related inhibitors K777 (1) and K11002 (2) ${ }^{[13]}$ have been investigated extensively as a potential treatment for American sleeping sickness ${ }^{[14]}$ (Chagas disease) caused by Trypanosoma cruzi (Figure 1). Biologically this organism and that causing HAT are closely related, and this similarity includes the structure of their major cysteinyl proteases. ${ }^{[11,12]}$ 


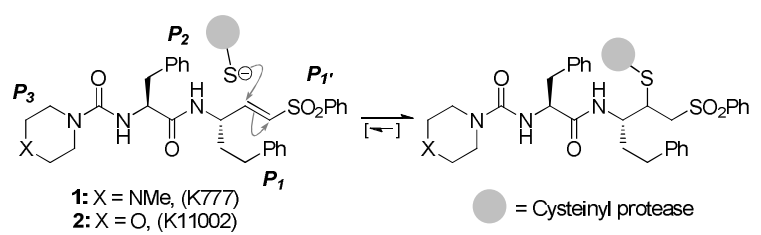

Figure 1. K777 (1) and K11002 (2), benchmark peptidic vinyl sulfone inhibitors and their interaction with parasitic cysteinyl proteases.

We have previously synthesized a range of dipeptidyl vinyl sulfone analogues of $\mathbf{1}$ in which the groups protruding into the $S 1$ ', S1 and S2 regions of the parasitic cysteinyl proteases (i.e. $\mathrm{P}_{1}, \mathrm{P}_{1}$ and $\mathrm{P}_{2}$ ) have been altered (for example, compound $\mathbf{3}$, Figure 2). ${ }^{[15]}$ The ability of this library to interfere with the lifecycle of Trypanosoma brucei brucei has been assessed and as part of this study azide $\mathbf{4}$ was also synthesized and evaluated. ${ }^{[16]}$ Based on the emergence of copper catalysed azide-alkyne click methodology ${ }^{[17,18]}$ (CuAAC) as a powerful chemical tool for the late-stage manipulation of biologically active structures, within which recognition, or reporting elements can be incorporated, we felt that compound $\mathbf{4}$ offered opportunities to rapidly diverge to access a range of $P_{1}$ substituted analogues from one intermediate.
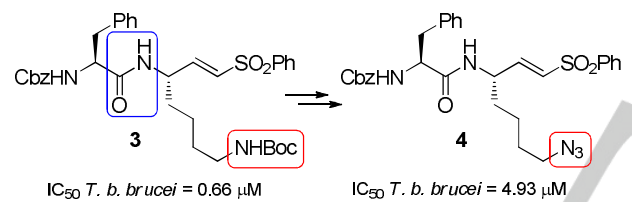

$\mathrm{IC}_{50} T$. b. bruce $i=4.93 \mu \mathrm{M}$ Site for $\mathrm{P} 1$ diversification via click chemistry
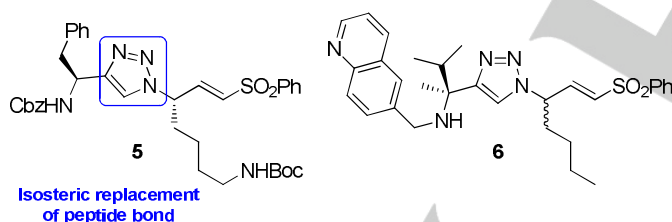
of peptide bond

Figure 2. Azide containing vinyl sulfone $\mathbf{4}$ and peptide bond bioisostere 5 .

In addition to optimization of binding affinity one might also consider the possible advantages of the replacement of the linear peptide bond, which can potentially confer low metabolic stability, poor membrane/intestinal permeability, low oral bioavailability, poor solubility and rapid clearance in vivo. ${ }^{[19]}$ One proven method to overcome the inherent problems of peptides is the replacement of the amide group with a non-labile bioisostere which can otherwise mimic the properties of the peptide. ${ }^{[2]}$ Since the advent of the CuAAC, 1,2,3-triazoles have become ubiquitous in peptidomimetic chemistry, serving amongst other things as a bioisostere for amide/peptide bonds due to their size, planarity and $\mathrm{H}$-bond accepting and donating abilities. ${ }^{[21]}$ In some cases, amide to triazole substitution has been proven to confer protease resistance when incorporated into the backbone of certain linear peptides. ${ }^{\text {[22] }}$ In 2008, Ellman and co-workers described a range of non-peptidic inhibitors against Chagas disease. ${ }^{[23]}$ Among this series was vinyl sulfone 6 (Figure 2) which comprised an L-norleucine group in the $\mathrm{P}_{1}$ position and a quinoline derived group in the $\mathrm{P}_{3}$ position. These two groups were linked by a 1,2,3-triazole (in place of an amide bond). One chemical issue uncovered in the course of the synthesis was a facile epimerization of the stereogenic centre beside the vinyl sulfone group and consequently this compound was evaluated as a mixture of epimers. Interestingly, during this evaluation no time dependence for the interaction of 6 with cruzain was found suggesting a competitive reversible mode of enzyme inhibition. Based on this precedent we were interested in probing what impact the removal of the native peptide bond and replacing this with a triazole would have on anti-trypanosomal activity (i.e. compound $\mathbf{3}$ vs compound 5, Figure 2). Recently we have explored an organocatalytic synthesis of compound $\mathbf{5}$ and its epimer. ${ }^{[24]}$

\section{Results and Discussion}

We initially focused on click-based analogues in the $P_{1}$ binding domain position. The $P_{1}$ region of the Trypanosomal cysteine proteases is located in the periphery of the polypeptide structure, thus, we felt that a range of substituents might be accommodated in this region with a view to increasing inhibitor binding/selectivity. To this end azide ${ }^{[16]} \quad \mathbf{4}$ and phenylacetylene/oct-1-yne/methyl propiolate/propargyl alcohol were treated with $\mathrm{CuSO}_{4} \cdot 5 \mathrm{H}_{2} \mathrm{O} / \mathrm{Na}$ ascorbate in $\mathrm{CH}_{2} \mathrm{Cl}_{2} / \mathrm{H}_{2} \mathrm{O}$, ${ }^{[25]}$ which generated triazoles 7-10 in good to excellent isolated yields. Gratifyingly, biotinylation, using the appropriate alkyne derived biotin ester ${ }^{[26]}$ and amide, ${ }^{[27]}$ also proved possible (compounds 11 and 12). Note, due to the insolubility of the amide derived biotin alkyne, the use of acetone/water as a homogeneous medium for the reactants was required. Based on the well-established avidin-biotin affinity purification technology ${ }^{[28]}$ it is felt that these compounds (11 and 12) offer possibilities as probes for elucidation of the target proteases and quantitative inhibitor assessment in cellular systems.

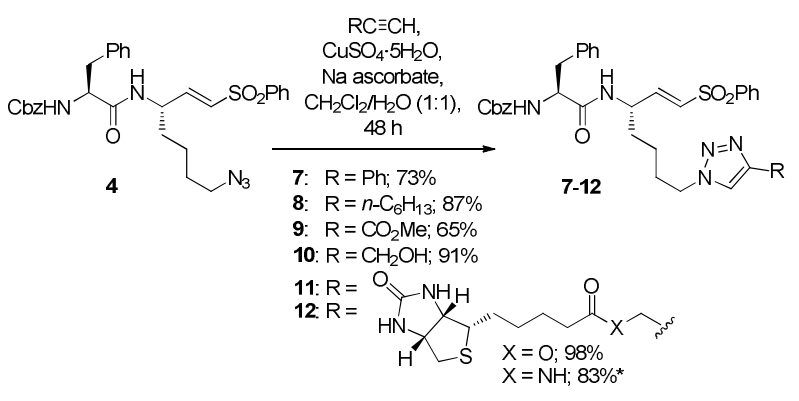

Scheme 1. Click reactions and click-based biotinylation (*acetone used instead of $\mathrm{CH}_{2} \mathrm{Cl}_{2}$ ). 
We then turned our attention to the synthesis of the 1,2,3triazole based bioisostere of compound $3^{[15]}$ utilising alkyne and azide-functionalised amino acids. ${ }^{[29]}$ We envisaged that the triazolyl vinyl sulfone of the type $\mathbf{5}$ could be accessed by two routes (route $A$ or $B$ ) involving alkyne 13 , which differ based on the timing of the copper catalysed alkyne-azide click reaction (CuAAC) and the Horner-Wadsworth Emmons (HWE) reaction (Scheme 2).

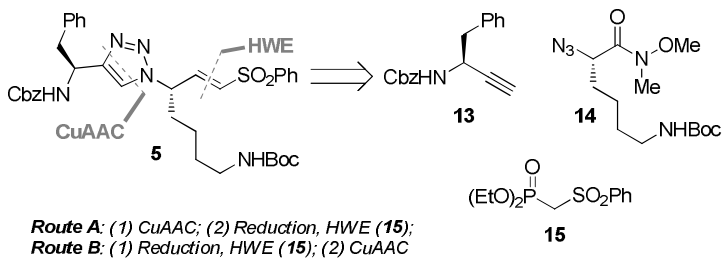

Scheme 2. Retrosynthetic analysis of triazole-based vinyl sulfone $\mathbf{5}$.

As a means to access alkyne 13 , aldehyde $16^{[30]}$ was treated with the Ohira Bestmann reagent ${ }^{[31]} \mathbf{1 7}$ in basic methanol which gave 13 directly in good yield (77\%). However, after chiral phase HPLC analysis it became apparent that racemization had occurred during this reaction. This undesired process presumably arises from the generation of methoxide in situ which appears incompatible with $\alpha$-substituted aldehydes of this type. ${ }^{[32,33]}$ Several attempts to ameliorate this racemization failed and the best result was obtained on slow dropwise addition of sub-stoichiometric equivalents of sodium methoxide to the Ohira Bestmann reagent 17, followed by dropwise addition of a solution of the aldehyde 16. However, this still resulted in the erosion of stereochemical integrity to $63 \%$ ee. Fortunately, our previous synthesis of alkyne 13 using the Corey-Fuchs method delivers enantiopure material. ${ }^{[24]}$ It is worth noting that some control over reaction conditions in this two-step sequence was necessary - in order to avoid loss of the $\mathrm{Cbz}$ group, in the first step and then gradual addition of $n$-BuLi in the second step to avoid the formation of side-product 19.

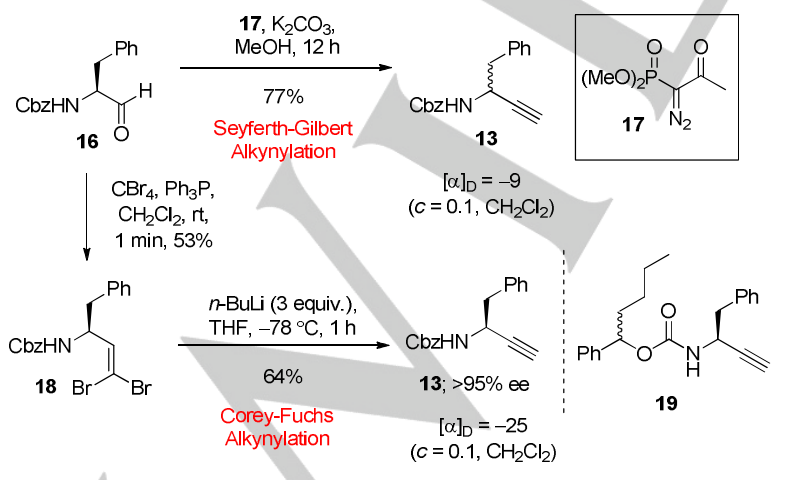

The azide coupling partner $\mathbf{1 4}$ was smoothly accessed from primary amine ${ }^{[34]} 20$ using the diazotransfer reagent $(\mathbf{2 1})$ of Goddard-Borger and co-workers. ${ }^{[35]}$ It is worth mentioning that $\alpha$-azido esters have been reported to be configurationally labile. ${ }^{[36]}$ Therefore, we also had concerns regarding the stereochemical integrity of $\mathbf{1 4}$ due to the enhanced acidity of the $\alpha$-proton. Fortunately, after chiral HPLC analysis, it was found that, in our hands, $\alpha$-azido Weinreb amides of this type do not suffer from this drawback and coupling partner 14 was accessed in, as far as we can ascertain, enantiopure form.

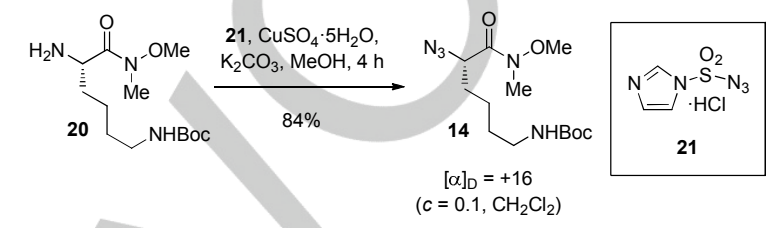

Scheme 4. Diazotransfer reaction.

Click reaction of Corey-Fuchs derived alkyne $\mathbf{1 3}$ with azide $\mathbf{1 4}$ gave the triazolyl Weinreb amide 22 as a single diastereomer (as determined by ${ }^{1} \mathrm{H}$ and ${ }^{13} \mathrm{C}$ NMR) in good yield (Scheme 5). This material was then chemoselectively reduced with $\mathrm{LiAlH}_{4}$ to give the triazolyl aldehyde $\mathbf{2 3}$ which was used immediately for the HWE reaction. However, upon olefination, under typical $\mathrm{NaH}$-based reaction conditions, an undesired alkene isomerization occurred. The desired vinyl sulfone $\mathbf{5}$ underwent complete isomerization to the allylic sulfone 24 (E:Z; 1:1), a process likely to be explained by the slight excess of the sodium salt of phosphonate $\mathbf{1 5}$ which is apparently basic enough to induce the alkene isomerization. Fortunately this situation was easily remedied using sub-stoichiometric amounts of base which gave the triazolyl vinyl sulfone $\mathbf{5}$ in moderate yield. Removal of the tert-butyloxycarbonyl group and $\mathrm{N}$-derivatisation was attempted using a method previously successful for compound $3^{[15,16]}$ However, upon addition of an electrophile and base $\left(\mathrm{Et}_{3} \mathrm{~N}\right)$ the alkene proved again to have undergone isomerization and thus the desired $\mathrm{N}$-substituted vinyl sulfone analogues (not shown) were not obtained.

The integrity of the vinyl sulfone in compound $\mathbf{5}$ was probed and bases such as $\mathrm{DBU}, \mathrm{Et}_{3} \mathrm{~N}$ and even the weak base $\mathrm{N}$-methyl morpholine can promote the vinyl to allyl isomerization. Due to the propensity of the vinyl to allyl isomerization, ${ }^{[37]}$ presumably facilitated by the presence of the aromatic triazole, we sought to improve upon this route and develop a more convergent synthesis which, as an added benefit, would also give us the flexibility to introduce a small range of non-amino acid based alkynes into the click reactions. With this in mind, a modified retrosynthetic strategy was considered whereby the order of the click and the HWE reactions was altered (Scheme 2, Route B). 

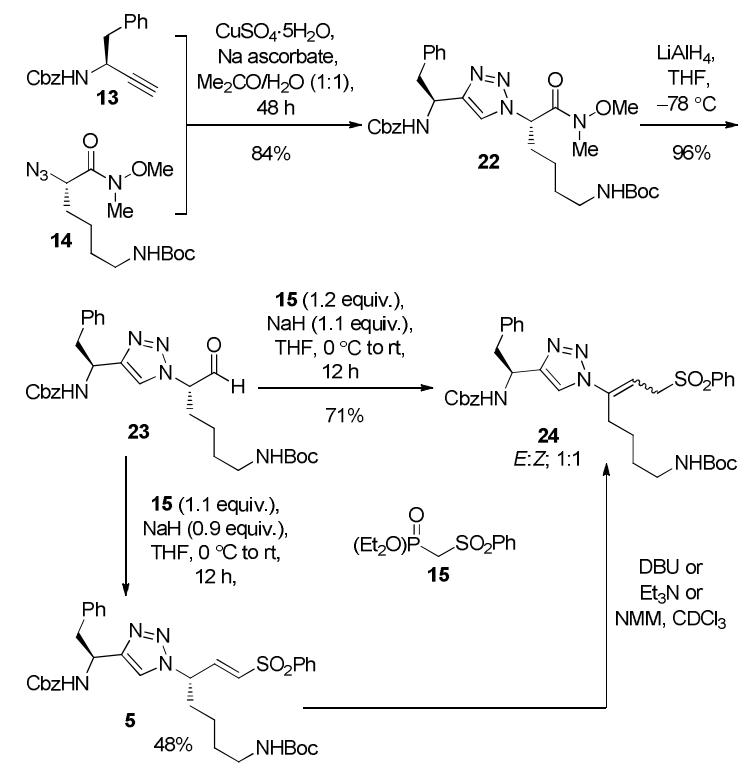

Scheme 5. Synthesis of 5 (Route A): Click reaction followed by HWE olefination.

As shown in Scheme 6, the synthesis of allylic azide $25^{[24]}$ commences from Fmoc-protected Weinreb amide ${ }^{[38]} 26$. Chemoselective reduction with $\mathrm{LiAlH}_{4}$ at $-78{ }^{\circ} \mathrm{C}$ gave amino aldehyde $^{[39]} 27$ in excellent yield without the need for column chromatography. This was converted into vinyl sulfone 28 in moderate yield, which, in the absence of the aromatic triazole ring flanking the $\alpha$-proton, gave no evidence of the previously problematic vinyl-allyl isomerization (e.g. 5 to $\mathbf{2 4}$, Scheme 5). Removal of the Fmoc group in this compound proved to be a considerable challenge due to the presence of an electrophilic vinyl sulfone moiety in the molecule and the requirement of nucleophilic conditions for the deprotection (e.g. the use of piperidine). Optimized conditions were found to be diethylamine in acetonitrile ${ }^{[40]}$ for a short reaction time. The free allylic amine (not shown) was found to be unstable, thus, the deprotected material was used crude in the diazotransfer reaction. Unfortunately, this reaction also proved problematic; and the conversion of compound $\mathbf{2 8}$ to allylic azide $\mathbf{2 5}$ (via an electron deficient allylic amine) resulted in a modest overall yield of $34 \%$.

Although allylic azide $\mathbf{2 5}$ was isolated in modest yield, enough material was available in order to investigate its click reaction with Corey-Fuchs derived alkyne 13, which under standard conditions, gave triazolyl vinyl sulfone $\mathbf{5}$. This material proved spectroscopically identical to the product from the previous synthesis (Scheme 5), with no evidence of racemization of the azide, or alkene isomerization. Allylic azide 25 additionally offers an avenue to diversify into non-peptidic inhibitors using structurally simpler alkynes. To this end, azide 25 was treated with the lipophilic alkynes, phenylacetylene and oct-1-yne, giving truncated inhibitors 29 and $\mathbf{3 0}$ in moderate yield, attributed to the electron deficient allylic azide. Thus, eleven novel vinyl sulfone and one allyl sulfone potential cysteine protease inhibitors have been prepared via a simple and efficient sequence which readily enables introduction of structural diversity into the $P_{1}$ and $P_{2}$ regions.

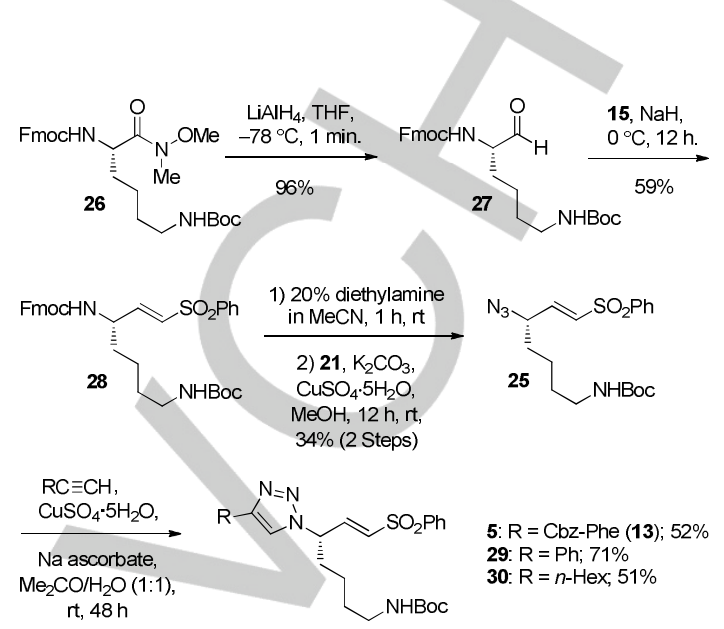

Scheme 6. Synthesis of 5 (Route B): HWE followed by Click reaction.

With the range of $P_{1}$ analogues (including biotinylated vinyl sulfones), two truncated $P_{3}$ analogues, amido-isosteric triazolyl vinyl sulfones and allyl sulfones in hand, the twelve potential inhibitors were evaluated against $T$. $b$. brucei using a wellestablished Alamar Blue cell viability assay. ${ }^{[41]}$ Table 1 illustrates the $\mathrm{EC}_{50}$ values obtained for the series and to benchmark these results, previously reported vinyl sulfones 3 and 4 were also included. $P_{1}$ substituted triazoles 7 to $\mathbf{1 1}$ displayed rather similar anti-trypanosomal activity, however replacement of the ester bond with an amide bond rendered compound 12 less potent. More specifically, the phenyl substituted analogue 7 , and aliphatic $n$-hexyl derivative 8 exhibited slightly improved activity compared with their azide counterpart 4. Ester and alcohol derived triazoles $\mathbf{9}$ and $\mathbf{1 0}$ respectively were less promising in terms of activity. Biotinylated ester derivative $\mathbf{1 1}$ exhibited comparable activity to $\mathbf{9}$ and $\mathbf{1 0}$ and on this basis might prove to be a useful probe for target pulldown with streptavidin. Bioisostere 5 retained anti-trypanosomal activity and was only slightly less active than its peptide counterpart 3. Somewhat surprisingly, allyl sulfone 24 retained its trypanosome killing potency $\left(E_{50}\right.$ of $\left.1.94 \mu \mathrm{M}\right)$, particularly since the electrophilic vinylic sulfone, generally assumed to be required for anti-trypanosomal activity, was not present. ${ }^{[42]}$ This finding widens opportunities for the future development of reversible inhibitors. It was interesting also to note that synthetic intermediates $\mathbf{2 5}$ and particularly 28 demonstrated micromolar/low micromolar activity especially considering the size of the lipophilic Fmoc group of 28. 
Table 1. Anti-trypanosomal activity of vinyl and allyl sulfones.

\begin{tabular}{clcl}
\hline Compound & $\mathrm{EC}_{50}(\mu \mathrm{M})$ & Compound & $\mathrm{EC}_{50}(\mu \mathrm{M})$ \\
\hline $\mathbf{3}^{[\mathrm{a}]}$ & 0.66 & $\mathbf{1 2}$ & $>10$ \\
$\mathbf{4}^{[\mathrm{b}]}$ & 4.93 & $\mathbf{5}$ & 2.66 \\
$\mathbf{7}$ & 2.13 & $E / Z-24$ & 1.94 \\
$\mathbf{8}$ & 1.14 & $\mathbf{2 5}$ & 8.56 \\
$\mathbf{9}$ & 4.24 & $\mathbf{2 8}$ & 1.63 \\
$\mathbf{1 0}$ & 4.47 & $\mathbf{2 9}$ & 6.11 \\
$\mathbf{1 1}$ & 4.17 & $\mathbf{3 0}$ & $>10$ \\
\hline
\end{tabular}

${ }^{[\mathrm{a}]}$ Reference 15. ${ }^{[\mathrm{b}]}$ Reference 16 .

In the light of the above findings a computational study was undertaken to gain insight into the interactions of the vinyl sulfone-based series of compounds within the active site of the Trypanosomal cathepsin B-like cysteine protease, rhodesain. Rhodesain possesses a two-domain fold typical of the papain cysteine protease superfamily, characterized by a very large hydrophobic $P_{1}$ pocket and a sterically restricted hydrophobic $P_{2}$ cleft as depicted in Figures 3-8. Figures 3-8 highlight the covalent interaction with Cys25 that all of the vinyl sulfone series make (with the exception of both isomers of allyl sulfone 24).

Figure 3 illustrates the binding pose of the amido-isosteric triazolyl vinyl sulfone, $\mathbf{5}$, compared with the previously reported binding pose of compound $\mathbf{3}^{\left[{ }^{15]}\right.}$ A 4 -fold difference in antitrypanosomal activity was observed in our whole-cell assays which is predicted to be in part due to the loss of a hydrogen bond interaction between the triazole peptide mimic and Asp161 when compared with the peptide bond of 3 . It is interesting to note that from our pose prediction a 1,2,4-triazole rather than a 1,2,3-triazole may offer additional binding affinity through the harnessing of an additional interaction with Asp161.

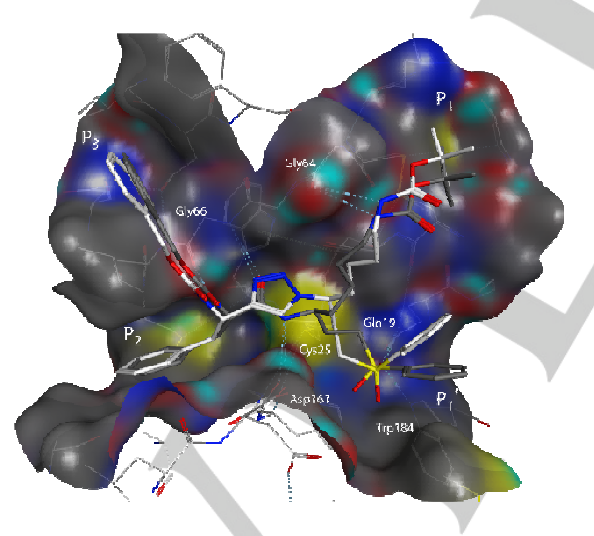

Figure 3. Binding poses of previously reported compound $3^{[15]}$ (Grey) and Compound 5 (White) in active site of rhodesain. Hashed lines denote hydrogen bonds between the ligand and cysteine protease.

Figure 4 shows the binding mode of $\mathbf{4}$, compared with $\mathbf{2 5}$, when both compounds are covalently attached to Cys25. It is of interest to note that allylic azide $\mathbf{2 5}$ appears to be a functional mimic of the carbonyl group of the amide bond and hydrogen bonding in both cases occurs with the backbone of Gly66.
Presumably the lower overall trypanosome killing activity of $\mathbf{2 5}$ is due to the absence of additional interactions in the $\mathrm{P}_{3}$ region.

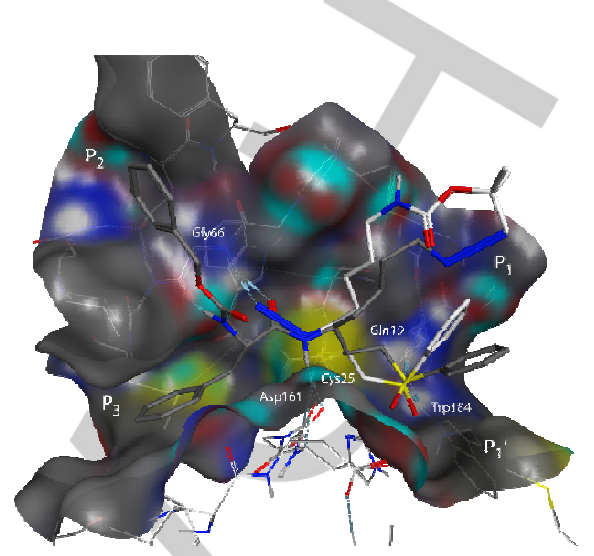

Figure 4. Binding poses of the azido containing compounds $4^{[16]}$ (Grey) and 25 (White) in active site of rhodesain. Hashed lines denote hydrogen bonds between the ligand and cysteine protease.

$P_{1}$ substituted triazoles $\mathbf{7 - 1 0}$, when covalently bound to rhodesain, adopt a similar binding conformation and relative position in the S1'-S3 subsites of rhodesain (Figure 5). A conserved network of polar $\mathrm{H}$-bond interactions were observed involving Gln19, Gly66, Asp161, and Trp 184 in active site of rhodesain which is reflected in the reasonably close antitrypanosomal $\mathrm{EC}_{50}$ values obtained for each compound (1-5 $\left.\mu \mathrm{M}\right)$.

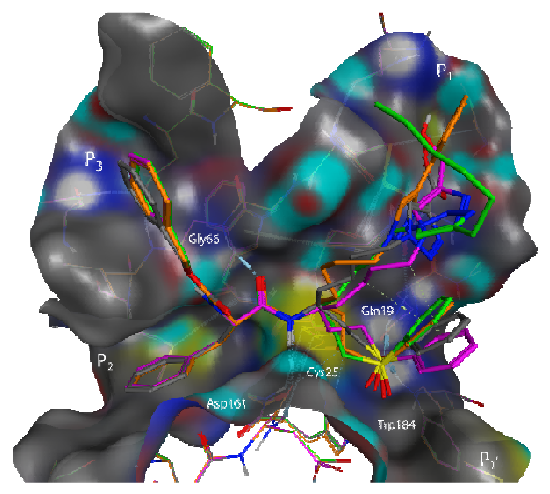

Figure 5. Binding poses of $P_{1}$ substituted triazoles 7 (orange), 8 (green), 9 (grey), $\mathbf{1 0}$ (magenta) in active site of rhodesain. Hashed lines denote hydrogen bonds between the ligand and cysteine protease.

The $P_{1}$ substituted biotinylated derivative 11 exhibited comparable potency with analogues $\mathbf{7 - 1 0}$, however the introduction of an amide bond compared with ester linkage significantly reduced its activity. Figure 6 also shows that 12 fails to occupy the same portion of a hydrophobic cleft probed by $\mathbf{1 1}$ possibly due to the enhanced rigidity of the amide compared with the ester bond. 


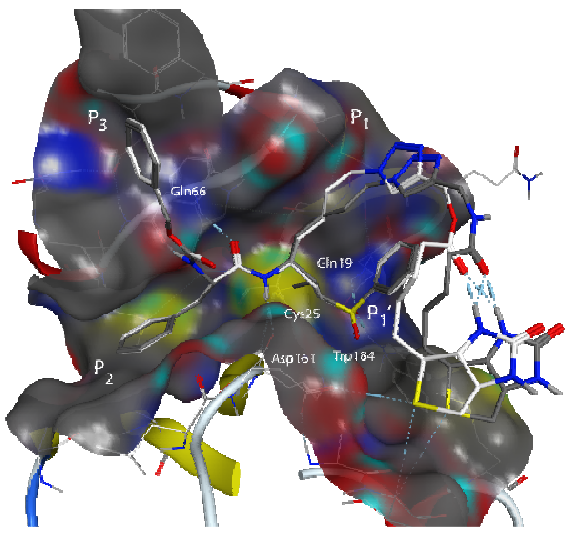

Figure 6. Binding poses of $P_{1}$ substituted triazoles 11 (white) and 12 (grey) in active site of rhodesain. Hashed lines denote hydrogen bonds between the ligand and cysteine protease.

It appears from our computational analysis that the $E$ isomer of $\mathbf{2 4}$ does not bind to rhodesain, since it cannot occupy a suitable conformation to facilitate $\mathrm{P}_{1} / \mathrm{P}_{1}$, subsite binding (Figure 7). In contrast, the Z-isomer of $\mathbf{2 4}$ occupies a highly similar position compared with compound $\mathbf{5}$. However, $\mathbf{2 4}$ is not capable of being stabilised via covalent interaction with Cys25. Based on this we hypothesise that isolation of the Z-isomer of compound 24 would not only significantly enhance its activity but also provide an alternative to irreversible inhibition of these cysteine proteases.

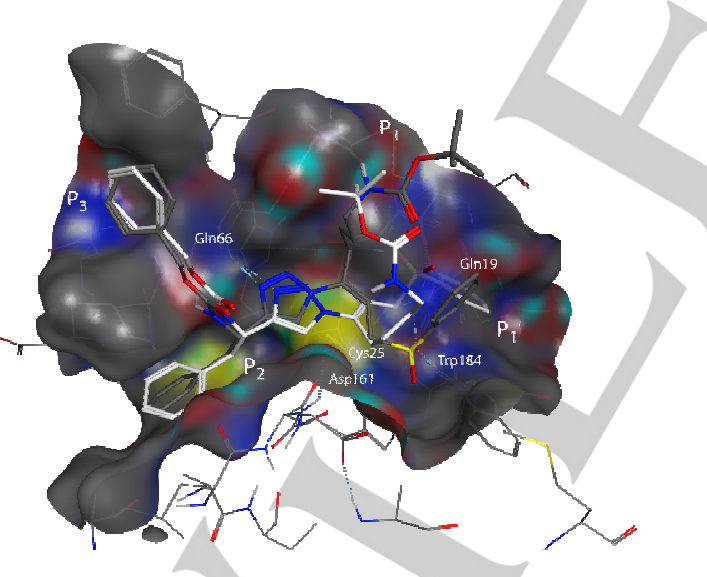

Figure 7. Binding poses of E-24 (white) and Z-24 (grey) in active site of rhodesain. Hashed lines denote hydrogen bonds between the ligand and cysteine protease.

\section{Conclusions}

To summarise, we have utilized click chemistry protocols to access structurally diverse triazolyl vinyl sulfone inhibitors of rhodesain with a particular emphasis on $\mathrm{P}_{1}$ inhibitors. We have shown that these compounds can be accessed via two distinct routes and the azide/alkyne precursors can be synthesized whilst maintaining stereochemical integrity. Problems encountered during the synthesis included the racemization of an $\alpha$-substituted aldehyde using the Ohira-Bestmann protocol which was remedied using the Corey-Fuchs procedure. The Ohira-Bestmann protocol appears to be incompatible in the synthesis of enantiopure propargylamine derivatives of this type and thus merits a caveat for chemists using this procedure with this type of $\alpha$-substituted aldehyde. Similar anti-trypanosomal activity was achieved with the more biologically resilient 1,2,3triazole in place of a peptide bond. Thus inhibitor 5 could prove to be more stable in vivo and may represent a step towards a possible orally available treatment for trypanosomiasis which would represent a significant advance upon current treatment procedures. Significantly the most potent compound of the series was found to be allyl triazolyl sulfone $\mathbf{2 4}$ which displayed good anti-trypanosomal activity and we reason that this could be a non-covalent inhibitor of cysteinyl proteases. The computational study supports the basis for incorporation of the triazole ring in place of an amide bond (analogues 5 and 24) and also clearly demonstrates that reversible inhibitors may offer an alternative route to cysteine protease inhibition in trypanosomes.

Overall, this work represents a means to access stereochemically pure triazolyl vinyl sulfones for cysteine protease inhibition with applications as inhibitors of $T$. b. brucei. It is our hope that these types of compounds might be used in other circumstances where cysteine proteases are known targets for therapeutic intervention.

\section{Experimental Section}

General experimental methods: ${ }^{1} \mathrm{H}$ and ${ }^{13} \mathrm{C}$ NMR spectra were recorded on Varian Unity $600 \mathrm{MHz}, 500 \mathrm{MHz}, 400 \mathrm{MHz}$ and $300 \mathrm{MHz}$ system spectrometers and coupling constants $(J)$ are quoted in Hertz. High resolution mass spectra were carried out on a VG analytical $70-E$ mass spectrometer. Infrared spectra were recorded on a Varian Instruments Excalibur series FT-IR 3100 spectrometer. Melting points were recorded on a Gallenkamp electrothermal melting point apparatus. Optical rotation data was obtained with a Perkin Elmer Model 343 polarimeter and values are quoted in units of $10^{-1} \mathrm{degcm}^{2} \mathrm{~g}^{-1}$. Reagents were obtained from commercial suppliers and were used without further purification. Tetrahydrofuran was freshly distilled from sodiumbenzophenone ketyl radical. Thin-layer chromatography was performed on silica coated aluminium sheets and compounds were visualized with UV light and aqueous potassium permanganate, or ninhydrin stain (for amines), followed by heating.

Benzyl \{(S)-1-oxo-3-phenyl-1-[((S,E)-7-(4-phenyl-1H-1,2,3-triazol-1yl)-1-(phenylsulfonyl)hept-1-en-3-yl)amino]propan-2-yl\}carbamate 7: General procedure for click reactions: To a vigorously stirred solution of azide $4^{[16]}(58 \mathrm{mg}, 0.1 \mathrm{mmol}, 1.0$ equiv.) and phenylacetylene $(12 \mu \mathrm{L}$, 0.11 mmol, 1.1 equiv.) in $\mathrm{CH}_{2} \mathrm{Cl}_{2} / \mathrm{H}_{2} \mathrm{O} ; 1: 1$ (1 mL) was added $\mathrm{CuSO}_{4} \cdot 5 \mathrm{H}_{2} \mathrm{O}(1 \mathrm{mg}, 0.004 \mathrm{mmol}, 0.05$ equiv.) and sodium ascorbate (3 $\mathrm{mg}, 0.015 \mathrm{mmol}, 0.2$ equiv.). The reaction mixture was stirred for 48 hours. The mixture was diluted with water $(5 \mathrm{~mL})$ and $\mathrm{CH}_{2} \mathrm{Cl}_{2}(5 \mathrm{~mL})$. The layers were separated and the aqueous layer was re-extracted with $\mathrm{CH}_{2} \mathrm{Cl}_{2}(2 \times 5 \mathrm{~mL})$. The combined organic layers were dried over $\mathrm{MgSO}_{4}$, filtered and solvent was removed in vacuo to give the crude product 
which was purified by column chromatography (c-Hex/EtOAc; $1: 1)$ to give triazole 7 as a white solid $(50 \mathrm{mg}, 73 \%)$. M.p. $=76-79{ }^{\circ} \mathrm{C}$. $\mathrm{R}_{f}=0.4(\mathrm{c}-$ Hex/EtOAc; 1:2). IR (film): $v_{\max }=3302,3137,3062,3034,2927,2859$, $1713,1663,1532,1447,1307,1287,1236,1146,1086 \mathrm{~cm}^{-1} .{ }^{1} \mathrm{H}$ NMR $\left(500 \mathrm{MHz}, \mathrm{CDCl}_{3}\right): \delta=1.20-1.34\left(\mathrm{~m}, 2 \mathrm{H}, \mathrm{CH}_{2}\right) 1.49-1.70\left(\mathrm{~m}, 2 \mathrm{H}, \mathrm{CH}_{2}\right)$ 1.76-1.96 (m, 2H, CH $)_{2} 2.91\left(\mathrm{dd}, J=14.0,7.5 \mathrm{~Hz}, 1 \mathrm{H}, \mathrm{CH}_{2}\right) 3.05(\mathrm{dd}, J=$ 14.0, $7.5 \mathrm{~Hz}, 1 \mathrm{H}, \mathrm{CH}_{2}$ ) 4.26-4.37 (m, 2H, $\left.\mathrm{CH}_{2}\right) 4.40$ (app. q, $J=7.5 \mathrm{~Hz}$, $1 \mathrm{H}, \mathrm{CH})$ 4.59-4.67 (m, 1H, CH) 4.98-5.08 (m, $\left.2 \mathrm{H}, \mathrm{CH}_{2}\right) 6.00(\mathrm{~d}, J=8.0$ $\mathrm{Hz}, 1 \mathrm{H}, \mathrm{NH}) 6.21(\mathrm{dd}, J=15.0,1.5 \mathrm{~Hz}, 1 \mathrm{H}, \mathrm{CH}) 6.45(\mathrm{~d}, J=7.5 \mathrm{~Hz}, 1 \mathrm{H}$, $\mathrm{NH}) 6.79(\mathrm{dd}, J=15.0,4.5 \mathrm{~Hz}, 1 \mathrm{H}, \mathrm{CH}) 7.08-7.12(\mathrm{~m}, 2 \mathrm{H}, \mathrm{ArH}) 7.13-7.16$ $(\mathrm{m}, 3 \mathrm{H}, \mathrm{ArH})$ 7.22-7.35 (m, 6H, ArH) 7.36-7.41 (m, 2H, ArH) 7.50-7.55 (m, $2 \mathrm{H}, \mathrm{ArH}) 7.60(\mathrm{t}, J=7.5 \mathrm{~Hz}, 1 \mathrm{H}, \mathrm{ArH}) 7.73(\mathrm{~s}, 1 \mathrm{H}, \mathrm{ArH}) 7.80(\mathrm{~d}, J=7.0$ $\mathrm{Hz}, 2 \mathrm{H}$, ArH) $7.84\left(\mathrm{~d}, J=7.5 \mathrm{~Hz}, 2 \mathrm{H}\right.$, ArH) ppm. ${ }^{13} \mathrm{C} \mathrm{NMR}(125 \mathrm{MHz}$, $\left.\mathrm{CDCl}_{3}\right): \delta=21.9\left(\mathrm{CH}_{2}\right) 29.2\left(\mathrm{CH}_{2}\right) 32.3\left(\mathrm{CH}_{2}\right) 38.2\left(\mathrm{CH}_{2}\right) 49.2\left(\mathrm{CH}_{2}\right) 49.3$ (CH) $57.0(\mathrm{CH}) 67.1\left(\mathrm{CH}_{2}\right) 119.9(\mathrm{CH}) 125.9(\mathrm{CH}) 127.2(\mathrm{CH}) 127.7(\mathrm{CH})$ $128.0(\mathrm{CH}) 128.2(\mathrm{CH}) 128.4(\mathrm{CH}) 128.6(\mathrm{CH}) 128.8(\mathrm{CH}) 129.0(\mathrm{CH})$ $129.3(\mathrm{CH}) 129.5(\mathrm{CH}) 130.4(\mathrm{C}) 130.6(\mathrm{CH}) 133.7(\mathrm{CH}) 136.3(\mathrm{C}) 136.5$ (C) 140.1 (C) 145.4 (CH) 148.0 (C) 156.4 (CO) 171.4 (CO) ppm. HRMS $\left(\mathrm{ES}^{+}\right) \mathrm{C}_{38} \mathrm{H}_{39} \mathrm{~N}_{5} \mathrm{O}_{5} \mathrm{NaS}\left(\mathrm{MNa}^{+}\right)$calcd. 700.2570; found 700.2554. [ $\left.\alpha\right]_{\mathrm{D}}=$ $-26\left(c=0.1, \mathrm{CH}_{2} \mathrm{Cl}_{2}\right)$. Anal. calcd. $\mathrm{C}_{38} \mathrm{H}_{39} \mathrm{~N}_{5} \mathrm{O}_{5} \mathrm{~S}: \mathrm{C}, 67.34 ; \mathrm{H}, 5.80 ; \mathrm{N}$, 10.33; found C, 67.07 ; H, 5.83; N, 9.98 .

Benzyl $\{(S)-1-[((S, E)-7-(4-h e x y l-1 H-1,2,3-t r i a z o l-1-y l)-1-$ (phenylsulfonyl)hept-1-en-3-yl)amino]-1-oxo-3-phenylpropan-2-

yl\}carbamate 8: As per general procedure: azide $4^{[16]}(30 \mathrm{mg}, 0.05 \mathrm{mmol}$, 1.0 equiv.), n-octyne (10 $\mu \mathrm{L}, 0.06 \mathrm{mmol}, 1.2$ equiv.), $\mathrm{CH}_{2} \mathrm{Cl}_{2} / \mathrm{H}_{2} \mathrm{O} ; 1: 1$ (1 $\mathrm{mL}$ ), $\mathrm{CuSO}_{4} \cdot 5 \mathrm{H}_{2} \mathrm{O}(1 \mathrm{mg}, 0.004 \mathrm{mmol}, 0.1$ equiv.) and sodium ascorbate ( $3 \mathrm{mg}, 0.015 \mathrm{mmol}, 0.3$ equiv.). Purification by column chromatography (c-Hex/EtOAc; $1: 1)$ gave triazole 8 as a white solid (31 mg, 87\%). M.p. = $88-90{ }^{\circ} \mathrm{C} . \mathrm{R}_{f}=0.4$ (c-Hex/EtOAc; 1:2). IR (film): $\mathrm{v}_{\max }=3306,2927,2857$, $1712,1661,1530,1447,1305,1256,1147,1085,1053,1028,749 \mathrm{~cm}^{-1}$. ${ }^{1} \mathrm{H}$ NMR $\left(500 \mathrm{MHz}, \mathrm{CDCl}_{3}\right): \delta=0.87\left(\mathrm{t}, J=7.0 \mathrm{~Hz}, 3 \mathrm{H}, \mathrm{CH}_{3}\right) 1.14-1.90$ $\left(\mathrm{m}, 14 \mathrm{H}, \mathrm{CH}_{2}\right) 2.68\left(\mathrm{t}, J=8.0 \mathrm{~Hz}, 2 \mathrm{H}, \mathrm{CH}_{2}\right) 2.95(\mathrm{dd}, J=14.0,8.0 \mathrm{~Hz}, 1 \mathrm{H}$ $\left.\mathrm{CH}_{2}\right) 3.08\left(\mathrm{dd}, J=14.0,6.5 \mathrm{~Hz}, 1 \mathrm{H}, \mathrm{CH}_{2}\right) 4.18-4.31\left(\mathrm{~m}, 2 \mathrm{H}, \mathrm{CH}_{2}\right) 4.38$ (app. q, $J=7.5 \mathrm{~Hz}, 1 \mathrm{H}, \mathrm{CH}) 4.56-4.64(\mathrm{~m}, 1 \mathrm{H}, \mathrm{CH}) 5.04\left(\mathrm{~s}, 2 \mathrm{H}, \mathrm{CH}_{2}\right)$ $6.03(\mathrm{~d}, J=8.0 \mathrm{~Hz}, 1 \mathrm{H}, \mathrm{NH}) 6.22(\mathrm{~d}, J=15.0 \mathrm{~Hz}, 1 \mathrm{H}, \mathrm{CH}) 6.39$ (s (br.), $1 \mathrm{H}, \mathrm{NH}) 6.78(\mathrm{dd}, J=15.0,4.5 \mathrm{~Hz}, 1 \mathrm{H}, \mathrm{CH}) 7.16-7.34(\mathrm{~m}, 11 \mathrm{H}, \mathrm{ArH})$ 7.51-7.56 (m, 2H, ArH) $7.62(\mathrm{t}, J=7.5 \mathrm{~Hz}, 1 \mathrm{H}, \operatorname{ArH}) 7.85(\mathrm{~d}, J=7.5 \mathrm{~Hz}$, $2 \mathrm{H}, \mathrm{ArH}) \mathrm{ppm} .{ }^{13} \mathrm{C} \mathrm{NMR}\left(125 \mathrm{MHz}, \mathrm{CDCl}_{3}\right): \delta=14.2\left(\mathrm{CH}_{3}\right) 21.9\left(\mathrm{CH}_{2}\right)$ $22.7\left(\mathrm{CH}_{2}\right) 25.8\left(\mathrm{CH}_{2}\right) 29.1\left(\mathrm{CH}_{2}\right) 29.3\left(\mathrm{CH}_{2}\right) 29.5\left(\mathrm{CH}_{2}\right) 31.7\left(\mathrm{CH}_{2}\right) 32.3$ $\left(\mathrm{CH}_{2}\right) 38.2\left(\mathrm{CH}_{2}\right) 48.9\left(\mathrm{CH}_{2}\right) 49.3(\mathrm{CH}) 57.0(\mathrm{CH}) 67.1\left(\mathrm{CH}_{2}\right) 120.8(\mathrm{CH})$ $127.2(\mathrm{CH}) 127.7(\mathrm{CH}) 128.0(\mathrm{CH}) 128.2(\mathrm{CH}) 128.6(\mathrm{CH}) 128.8(\mathrm{CH})$ $129.3(\mathrm{CH}) 129.4(\mathrm{CH}) 130.6(\mathrm{CH}) 133.6(\mathrm{CH}) 136.3(\mathrm{C}) 136.6(\mathrm{C}) 140.2$ (C) $145.3(\mathrm{CH}) 148.8$ (C) 156.4 (CO) 171.3 (CO) ppm. HRMS (ES $\left.{ }^{+}\right)$ $\mathrm{C}_{38} \mathrm{H}_{48} \mathrm{~N}_{5} \mathrm{O}_{5} \mathrm{~S}\left(\mathrm{MH}^{+}\right)$calcd. 686.3376; found 686.3375. [a] $]_{D}=-22(c=0.1$, $\mathrm{CH}_{2} \mathrm{Cl}_{2}$ ).

Methyl 1-\{(S,E)-5-((S)-2-[((benzyloxy)carbonyl)amino)-3phenylpropanamido]-7-(phenylsulfonyl)hept-6-en-1-yl\}-1 H-1,2,3-

triazole-4-carboxylate 9: As per general procedure: azide $4^{[16]}(40 \mathrm{mg}$, $0.07 \mathrm{mmol}, 1.0$ equiv.), methyl propiolate ( $9 \mu \mathrm{L}, 0.11 \mathrm{mmol}, 1.5$ equiv.), $\mathrm{CH}_{2} \mathrm{Cl}_{2} / \mathrm{H}_{2} \mathrm{O} ; 1: 1$ (1 mL), $\mathrm{CuSO}_{4} \cdot 5 \mathrm{H}_{2} \mathrm{O}$ (1 mg, $0.004 \mathrm{mmol}, 0.05$ equiv.) and sodium ascorbate $(2 \mathrm{mg}, 0.01 \mathrm{mmol}, 0.1$ equiv.). Purification by column chromatography ( $c$-Hex/EtOAc; $1: 1)$ gave triazole 9 as a white solid (30 mg, 65\%). M.p. $=61-63{ }^{\circ} \mathrm{C} . \mathrm{R}_{f}=0.4$ (c-Hex/EtOAc; 1:3). IR (film): $v_{\max }=3308,3140,3061,3033,2951,2927,2856,1721,1665$, $1531,1446,1371,1307,1288,1230,1146,1086,1044 \mathrm{~cm}^{-1} .{ }^{1} \mathrm{H}$ NMR $\left(400 \mathrm{MHz}, \mathrm{CDCl}_{3}\right): \delta=1.18-1.35\left(\mathrm{~m}, 2 \mathrm{H}, \mathrm{CH}_{2}\right) 1.40-1.66\left(\mathrm{~m}, 2 \mathrm{H}, \mathrm{CH}_{2}\right)$ 1.74-1.97 (m, 2H, $\left.\mathrm{CH}_{2}\right) 2.97\left(\mathrm{dd}, J=14.0,7.0 \mathrm{~Hz}, 1 \mathrm{H}, \mathrm{CH}_{2}\right) 3.04(\mathrm{dd}, J=$ $\left.14.0,7.0 \mathrm{~Hz}, 1 \mathrm{H}, \mathrm{CH}_{2}\right) 3.90\left(\mathrm{~s}, 3 \mathrm{H}, \mathrm{CH}_{3}\right) 4.24-4.40\left(\mathrm{~m}, 3 \mathrm{H}, \mathrm{CH}_{2}+\mathrm{CH}\right)$ 4.60-4.68 (m, 1H, CH) $5.02\left(\mathrm{~s}, 2 \mathrm{H}, \mathrm{CH}_{2}\right) 5.65(\mathrm{~d}, J=7.5 \mathrm{~Hz}, 1 \mathrm{H}, \mathrm{NH})$ $6.14(\mathrm{dd}, J=15.0,1.5 \mathrm{~Hz}, 1 \mathrm{H}, \mathrm{CH}) 6.35(\mathrm{~d}, J=8.5 \mathrm{~Hz}, 1 \mathrm{H}, \mathrm{NH}) 6.77$ (dd, $J=15.0,4.5 \mathrm{~Hz}, 1 \mathrm{H}, \mathrm{CH}) 7.12-7.22(\mathrm{~m}, 5 \mathrm{H}, \mathrm{ArH})$ 7.23-7.34 (m, 5H, ArH) 7.52-7.58 (m, 2H, ArH) 7.60-7.66 (m, $1 \mathrm{H}, \operatorname{ArH}) 7.84(\mathrm{~d}, J=7.5 \mathrm{~Hz}, 2 \mathrm{H}$,
ArH) $8.07(\mathrm{~s}, 1 \mathrm{H}, \mathrm{ArH}) \mathrm{ppm} .{ }^{13} \mathrm{C} \mathrm{NMR}\left(100 \mathrm{MHz}, \mathrm{CDCl}_{3}\right): \delta=22.0\left(\mathrm{CH}_{2}\right)$ $29.1\left(\mathrm{CH}_{2}\right) 32.9\left(\mathrm{CH}_{2}\right) 38.0\left(\mathrm{CH}_{2}\right) 48.8(\mathrm{CH}) 49.9\left(\mathrm{CH}_{2}\right) 52.2\left(\mathrm{CH}_{3}\right) 56.8$ $(\mathrm{CH}) 67.0\left(\mathrm{CH}_{2}\right) 127.2(\mathrm{CH}) 127.5(\mathrm{CH}) 127.6(\mathrm{CH}) 128.0(\mathrm{CH}) 128.2$ (CH) $128.5(\mathrm{CH}) 128.7(\mathrm{CH}) 129.2(\mathrm{CH}) 129.4(\mathrm{CH}) 130.6(\mathrm{CH}) 133.6$ (CH) 136.1 (C) 136.2 (C) $139.9(2 \times$ C) $145.1(\mathrm{CH}) 156.1(\mathrm{CO}) 161.2$ (CO) 171.0 (CO) ppm. HRMS (ES $)_{34} \mathrm{H}_{37} \mathrm{~N}_{5} \mathrm{O}_{7} \mathrm{NaS}\left(\mathrm{MNa}^{+}\right)$calcd. 682.2311; found 682.2311. [ $\alpha]_{\mathrm{D}}=-6\left(c=0.1, \mathrm{CH}_{2} \mathrm{Cl}_{2}\right)$.

Benzyl \{(S)-1-[((S,E)-7-(4-(hydroxymethyl)-1H-1,2,3-triazol-1-yl)-1(phenylsulfonyl)hept-1-en-3-yl)amino]-1-oxo-3-phenylpropan-2-

yl\}carbamate 10: As per general procedure: azide $4^{[16]}(30 \mathrm{mg}, 0.05$ mmol, 1.0 equiv.), propargyl alcohol ( $13.5 \mu \mathrm{L}, 0.23 \mathrm{mmol}, 4.5$ equiv.), $\mathrm{CH}_{2} \mathrm{Cl}_{2} / \mathrm{H}_{2} \mathrm{O} ; 1: 1$ (1 mL), CuSO $4 \cdot 5 \mathrm{H}_{2} \mathrm{O}(1 \mathrm{mg}, 0.004 \mathrm{mmol}, 0.1$ equiv.) and sodium ascorbate $(2 \mathrm{mg}, 0.01 \mathrm{mmol}, 0.2$ equiv.). Purification by column chromatography $\left(\mathrm{CH}_{2} \mathrm{Cl}_{2} / \mathrm{MeOH} ; 15: 1\right)$ gave triazole 10 as a white solid (30 mg, 91\%). M.p. $=46-48{ }^{\circ} \mathrm{C} . \mathrm{R}_{f}=0.3\left(\mathrm{CH}_{2} \mathrm{Cl}_{2} / \mathrm{MeOH} ; 15: 1\right)$ IR (film): $v_{\max }=3295,3062,2927,2860,1707,1663,1536,1447,1307$, $1287,1259,1145,1085,1052 \mathrm{~cm}^{-1} .{ }^{1} \mathrm{H}$ NMR $\left(400 \mathrm{MHz}, \mathrm{CDCl}_{3}\right): \delta=$ 1.04-1.34 (m, 2H, $\left.\mathrm{CH}_{2}\right)$ 1.38-1.66 (m, 2H, $\left.\mathrm{CH}_{2}\right)$ 1.74-1.96 (m, 2H, $\left.\mathrm{CH}_{2}\right)$ $2.88(\mathrm{~s}(\mathrm{br}), 1 \mathrm{H}, \mathrm{OH})$ 2.94-3.08 (m, 2H, $\left.\mathrm{CH}_{2}\right)$ 4.23-4.45 (m, 3H, $\mathrm{CH}_{2}+$ $\mathrm{CH}) 4.52-4.63(\mathrm{~m}, 1 \mathrm{H}, \mathrm{CH}) 4.76\left(\mathrm{~s}, 2 \mathrm{H}, \mathrm{CH}_{2}\right) 5.00-5.10\left(\mathrm{~m}, 2 \mathrm{H}, \mathrm{CH}_{2}\right) 5.77$ $(\mathrm{s}, 1 \mathrm{H}, \mathrm{NH}) 6.06(\mathrm{~d}, J=15.0 \mathrm{~Hz}, 1 \mathrm{H}, \mathrm{CH}) 6.18(\mathrm{~d}, J=8.5 \mathrm{~Hz}, 1 \mathrm{H}, \mathrm{NH})$ $6.72(\mathrm{dd}, J=15.0,4.5 \mathrm{~Hz}, 1 \mathrm{H}, \mathrm{CH}) 7.13-7.24(\mathrm{~m}, 5 \mathrm{H}, \mathrm{ArH})$ 7.25-7.37 (m, $5 \mathrm{H}, \mathrm{ArH}) 7.47-7.59(\mathrm{~m}, 3 \mathrm{H}, \mathrm{ArH}) 7.64(\mathrm{t}, J=7.5 \mathrm{~Hz}, 1 \mathrm{H}, \mathrm{ArH}) 7.84(\mathrm{~d}, J=$ $7.5 \mathrm{~Hz}, 2 \mathrm{H}, \mathrm{ArH}) \mathrm{ppm} .{ }^{13} \mathrm{C} \mathrm{NMR}\left(100 \mathrm{MHz}, \mathrm{CDCl}_{3}\right): \delta=21.8\left(\mathrm{CH}_{2}\right) 29.0$ $\left(\mathrm{CH}_{2}\right) 32.5\left(\mathrm{CH}_{2}\right) 38.4\left(\mathrm{CH}_{2}\right) 49.0(\mathrm{CH}) 49.4\left(\mathrm{CH}_{2}\right) 56.4\left(\mathrm{CH}+\mathrm{CH}_{2}\right) 67.1$ $\left(\mathrm{CH}_{2}\right) 127.1(\mathrm{CH}) 127.6(\mathrm{CH}) 127.9(2 \times \mathrm{CH}) 128.2(\mathrm{CH}) 128.5(\mathrm{CH})$ $128.6(\mathrm{CH}) 129.2(\mathrm{CH}) 129.3(\mathrm{CH}) 130.4(\mathrm{CH}) 133.6(\mathrm{CH}) 136.1(\mathrm{C})$ $136.2(\mathrm{C}) 140.0(2 \times \mathrm{CH}) 145.5(\mathrm{CH}) 156.2(\mathrm{CO}) 171.2(\mathrm{CO}) \mathrm{ppm}$. HRMS $\left(\mathrm{ES}^{+}\right) \mathrm{C}_{33} \mathrm{H}_{37} \mathrm{~N}_{5} \mathrm{O}_{6} \mathrm{NaS}\left(\mathrm{MNa}^{+}\right)$calcd. 654.2362; found 654.2348. [a] $]_{\mathrm{D}}=-6$ $\left(C=0.1, \mathrm{CH}_{2} \mathrm{Cl}_{2}\right.$ ).

\section{$\{1-[(S, E)-5-((S)-2-(((B e n z y l o x y)$ carbonyl)amino)-3-}

phenylpropanamido)-7-(phenylsulfonyl)hept-6-en-1-yl]-1 H-1,2,3-

triazol-4-yl\}methyl $\quad 5$-[(3aS,4S,6a $R)$-2-oxohexahydro-1 $H$-thieno[3,4d] imidazol-4-yl]pentanoate 11: Azide $4^{[16]}(35 \mathrm{mg}, 0.06 \mathrm{mmol}, 1.0$ equiv.), biotin ester alkyne ${ }^{[26]}(17 \mathrm{mg}, 0.06 \mathrm{mmol}, 1.0$ equiv.) and $\mathrm{CuSO}_{4} \cdot 5 \mathrm{H}_{2} \mathrm{O}$ ( $1 \mathrm{mg}, 0.005 \mathrm{mmol}, 0.05$ equiv.) was vigorously stirred in $\mathrm{CH}_{2} \mathrm{Cl}_{2} / \mathrm{H}_{2} \mathrm{O} ; 1: 1$ (2 mL). Na ascorbate $(4 \mathrm{mg}, 0.02 \mathrm{mmol}, 0.3$ equiv.) was added and the mixture was left to stir for 48 hours. Solvent was removed in vacuo and the crude product was purified by column chromatography $\left(\mathrm{CH}_{2} \mathrm{Cl}_{2} / \mathrm{MeOH} ; 4: 1\right)$ to give triazole 11 as a white powdery solid (51 mg, $>95 \%$ ). M.p. $=65-68{ }^{\circ} \mathrm{C} . \mathrm{R}_{f}=0.6\left(\mathrm{CH}_{2} \mathrm{Cl}_{2} / \mathrm{MeOH} ; 4: 1\right)$. IR (film): $\mathrm{v}_{\max }=$ $3274,3061,2928,2860,1699,1539,1497,1455,1447,1307,1287$, $1265,1146,1086,735 \mathrm{~cm}^{-1} .{ }^{1} \mathrm{H}$ NMR $\left(600 \mathrm{MHz}, \mathrm{CDCl}_{3}\right): \delta=1.21-1.31$ $\left(\mathrm{m}, 4 \mathrm{H}, \mathrm{CH}_{2}\right)$ 1.32-1.40 (m, 2H, $\left.\mathrm{CH}_{2}\right)$ 1.44-1.69 (m, 4H, $\left.\mathrm{CH}_{2}\right)$ 1.75-1.91 $\left(\mathrm{m}, 2 \mathrm{H}, \mathrm{CH}_{2}\right) 2.32\left(\mathrm{t}, J=7.0 \mathrm{~Hz}, 2 \mathrm{H}, \mathrm{CH}_{2}\right) 2.65\left(\mathrm{~d}, J=13.0 \mathrm{~Hz}, 1 \mathrm{H}, \mathrm{CH}_{2}\right)$ 2.84 (dd, $\left.J=13.0,5.0 \mathrm{~Hz}, 1 \mathrm{H}, \mathrm{CH}_{2}\right) 2.93$ (dd, $J=13.5,7.5 \mathrm{~Hz}, 1 \mathrm{H}, \mathrm{CH}_{2}$ ) $3.00\left(\mathrm{dd}, J=13.5,7.5 \mathrm{~Hz}, 1 \mathrm{H}, \mathrm{CH}_{2}\right) 3.08(\mathrm{td}, J=7.5,4.5 \mathrm{~Hz}, 1 \mathrm{H}, \mathrm{CH})$ 4.19-4.23 (m, 1H, CH) 4.23-4.30 (m, 2H, $\left.\mathrm{CH}_{2}\right) 4.40-4.44(\mathrm{~m}, 1 \mathrm{H}, \mathrm{CH})$ 4.48 (app. q, $J=7.5 \mathrm{~Hz}, 1 \mathrm{H}, \mathrm{CH}) 4.54-4.61(\mathrm{~m}, 1 \mathrm{H}, \mathrm{CH}) 5.00(\mathrm{~d}, J=12.5$ $\left.\mathrm{Hz}, 1 \mathrm{H}, \mathrm{CH}_{2}\right) 5.04\left(\mathrm{~d}, J=12.5 \mathrm{~Hz}, 1 \mathrm{H}, \mathrm{CH}_{2}\right) 5.19(\mathrm{~d}, J=13.0 \mathrm{~Hz}, 1 \mathrm{H}$, $\left.\mathrm{CH}_{2}\right) 5.22\left(\mathrm{~d}, J=13.0 \mathrm{~Hz}, 1 \mathrm{H}, \mathrm{CH}_{2}\right) 5.52(\mathrm{~s}, 1 \mathrm{H}, \mathrm{NH}) 5.96(\mathrm{~s}, 1 \mathrm{H}, \mathrm{NH})$ $6.08(\mathrm{~d}, J=15.0 \mathrm{~Hz}, 1 \mathrm{H}, \mathrm{CH}) 6.13(\mathrm{~d}, J=8.0 \mathrm{~Hz}, 1 \mathrm{H}, \mathrm{NH}) 6.76(\mathrm{dd}, J=$ 15.0, $4.5 \mathrm{~Hz}, 1 \mathrm{H}, \mathrm{CH}) 7.08-7.20(\mathrm{~m}, 5 \mathrm{H}, \operatorname{ArH}) 7.25(\mathrm{~d}, J=7.0 \mathrm{~Hz}, 2 \mathrm{H}$, ArH) $7.27-7.33(\mathrm{~m}, 3 \mathrm{H}, \mathrm{ArH}) 7.36(\mathrm{~d}, J=8.0 \mathrm{~Hz}, 1 \mathrm{H}, \mathrm{NH}) 7.55$ (app. t, $J=$ $7.5 \mathrm{~Hz}, 2 \mathrm{H}$ ArH) $7.63(\mathrm{t}, J=7.5 \mathrm{~Hz}, 1 \mathrm{H}, \mathrm{ArH}) 7.67(\mathrm{~s}, 1 \mathrm{H}, \mathrm{ArH}) 7.83(\mathrm{~d}, J$ $=7.5 \mathrm{~Hz}, 2 \mathrm{H}, \mathrm{ArH}) \mathrm{ppm} .{ }^{13} \mathrm{C} \mathrm{NMR}\left(150 \mathrm{MHz}, \mathrm{CDCl}_{3}\right): \delta=22.2\left(\mathrm{CH}_{2}\right) 24.7$ $\left(\mathrm{CH}_{2}\right) 28.0\left(2 \times \mathrm{CH}_{2}\right) 29.4\left(\mathrm{CH}_{2}\right) 32.9\left(\mathrm{CH}_{2}\right) 32.9\left(\mathrm{CH}_{2}\right) 33.7\left(\mathrm{CH}_{2}\right) 38.5$ $\left(\mathrm{CH}_{2}\right) 40.6\left(\mathrm{CH}_{2}\right) 49.1(\mathrm{CH}) 49.7\left(\mathrm{CH}_{2}\right) 55.4(\mathrm{CH}) 56.4(\mathrm{CH}) 57.6\left(\mathrm{CH}_{2}\right)$ $60.1(\mathrm{CH}) 61.8(\mathrm{CH}) 66.9\left(\mathrm{CH}_{2}\right) 124.0(\mathrm{CH}) 127.0(\mathrm{CH}) 127.6(\mathrm{CH}) 127.8$ $(\mathrm{CH}) 128.1(\mathrm{CH}) 128.5(\mathrm{CH}) 128.6(\mathrm{CH}) 129.27(\mathrm{CH}) 129.31(\mathrm{CH}) 130.2$

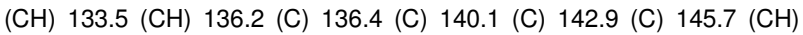
156.2 (CO) 163.6 (CO) 171.4 (CO) 173.5 (CO) ppm. HRMS (ES $\left.{ }^{+}\right)$ 
$\mathrm{C}_{43} \mathrm{H}_{51} \mathrm{~N}_{7} \mathrm{O}_{8} \mathrm{NaS}_{2}\left(\mathrm{MNa}^{+}\right)$calcd. 880.3138; found 880.3139. [ $\left.\alpha\right]_{\mathrm{D}}=+17(\mathrm{c}$ $=0.1, \mathrm{CH}_{2} \mathrm{Cl}_{2}$ ).

Benzyl \{(S)-1-oxo-1-[((S,E)-7-(4-)((5-((3aS,4S,6aR)-2-oxohexahydro$1 H$-thieno[3,4- $d]$ imidazol-4-yl)pentanamido)methyl)-1 $H$-1,2,3-triazol1-yl)-1-(phenylsulfonyl)hept-1-en-3-yl)amino]-3-phenylpropan-2yl\}carbamate 12: Azide $4^{[16]}$ (30 mg, $0.05 \mathrm{mmol}, 1.0$ equiv.), biotin amide alkyne $^{[27]}\left(15 \mathrm{mg}, 0.05 \mathrm{mmol}, 1.0\right.$ equiv.) and $\mathrm{CuSO}_{4} \cdot 5 \mathrm{H}_{2} \mathrm{O}(1 \mathrm{mg}, 0.005$ mmol, 0.1 equiv.) were stirred in $\mathrm{Me}_{2} \mathrm{CO} / \mathrm{H}_{2} \mathrm{O} ; 1: 1$ (2 mL). $\mathrm{Na}$ ascorbate ( $3 \mathrm{mg}, 0.015 \mathrm{mmol}, 0.3$ equiv.) was added and the reaction mixture was stirred for 48 hours. Solvent was removed in vacuo and the crude product was purified by column chromatography (EtOAc/MeOH; 10:1 $\rightarrow$ 4:1) to give triazole 12 as an off white solid (37 mg, 83\%). M.p. $=67-$ $71^{\circ} \mathrm{C} . \mathrm{R}_{f}=0.5(\mathrm{EtOAc} / \mathrm{MeOH} ; 4: 1)$. IR (film): $\mathrm{v}_{\max }=3278,3060,2931$, $2862,1697,1542,1535,1498,1455,1447,1306,1286,1265,1145$, $1085,1054,1027,834,735 \mathrm{~cm}^{-1}$. ${ }^{1} \mathrm{H}$ NMR $\left(600 \mathrm{MHz}, \mathrm{CDCl}_{3}\right): \delta=1.15-$ $1.45\left(\mathrm{~m}, 4 \mathrm{H}, \mathrm{CH}_{2}\right)$ 1.49-1.69 (m, 6H, $\left.\mathrm{CH}_{2}\right)$ 1.70-1.88 (m, 2H, $\left.\mathrm{CH}_{2}\right)$ 2.10$2.22\left(\mathrm{~m}, 2 \mathrm{H}, \mathrm{CH}_{2}\right) 2.66\left(\mathrm{~d}, J=12.5 \mathrm{~Hz}, 1 \mathrm{H}, \mathrm{CH}_{2}\right) 2.84(\mathrm{dd}, J=12.5,5.0$ $\left.\mathrm{Hz}, 1 \mathrm{H}, \mathrm{CH}_{2}\right) 2.93\left(\mathrm{dd}, J=13.0,7.0 \mathrm{~Hz}, 1 \mathrm{H}, \mathrm{CH}_{2}\right) 3.00(\mathrm{dd}, J=13.0,7.0$ $\mathrm{Hz}, 1 \mathrm{H}, \mathrm{CH}_{2}$ ) 3.07 (app. q, $\left.J=7.0 \mathrm{~Hz}, 1 \mathrm{H}, \mathrm{CH}\right) 4.15-4.31\left(\mathrm{~m}, 3 \mathrm{H}, \mathrm{CH}_{2}+\right.$ CH) 4.36-4.54 (m, 4H, CH $+2 \times \mathrm{CH}) 4.55-4.61(\mathrm{~m}, 1 \mathrm{H}, \mathrm{CH}) 4.99(\mathrm{~d}, J=$ $\left.12.5 \mathrm{~Hz}, 1 \mathrm{H}, \mathrm{CH}_{2}\right) 5.04\left(\mathrm{~d}, J=12.5 \mathrm{~Hz}, 1 \mathrm{H}, \mathrm{CH}_{2}\right) 5.95(\mathrm{~s}, 1 \mathrm{H}, \mathrm{NH}) 6.10(\mathrm{~d}$, $J=15.0 \mathrm{~Hz}, 1 \mathrm{H}, \mathrm{CH}) 6.15(\mathrm{~d}, J=8.0 \mathrm{~Hz}, 1 \mathrm{H}, \mathrm{NH}) 6.71(\mathrm{~s}, 1 \mathrm{H}, \mathrm{NH}) 6.76$ (dd, $J=15.0,4.5 \mathrm{~Hz}, 1 \mathrm{H}, \mathrm{CH}) 7.08-7.20(\mathrm{~m}, 6 \mathrm{H}, \mathrm{ArH}) 7.25(\mathrm{~d}, J=7.0 \mathrm{~Hz}$, $1 \mathrm{H}, \mathrm{NH}) 7.26-7.33(\mathrm{~m}, 4 \mathrm{H}, \mathrm{ArH}) 7.44(\mathrm{~d}, J=8.0 \mathrm{~Hz}, 1 \mathrm{H}, \mathrm{NH}) 7.54$ (app. t, $J=7.5 \mathrm{~Hz}, 2 \mathrm{H}, \mathrm{ArH}) 7.60-7.64(\mathrm{~m}, 1 \mathrm{H}, \mathrm{ArH}) 7.65(\mathrm{~s}, 1 \mathrm{H}, \mathrm{ArH}) 7.83(\mathrm{~d}, J=$ $7.5 \mathrm{~Hz}, 2 \mathrm{H}, \mathrm{ArH}) \mathrm{ppm} .{ }^{13} \mathrm{C}$ NMR $\left(150 \mathrm{MHz}, \mathrm{CDCl}_{3}\right): \delta=22.1\left(\mathrm{CH}_{2}\right) 25.4$ $\left(\mathrm{CH}_{2}\right) 27.96\left(\mathrm{CH}_{2}\right) 28.04\left(\mathrm{CH}_{2}\right) 29.3\left(\mathrm{CH}_{2}\right) 32.9\left(\mathrm{CH}_{2}\right) 34.6\left(\mathrm{CH}_{2}\right) 35.6$ $\left(\mathrm{CH}_{2}\right) 38.6\left(\mathrm{CH}_{2}\right) 40.7\left(\mathrm{CH}_{2}\right) 49.2(\mathrm{CH}) 49.7\left(\mathrm{CH}_{2}\right) 55.8(\mathrm{CH}) 56.3(\mathrm{CH})$ $60.1(\mathrm{CH}) 61.8(\mathrm{CH}) 66.9\left(\mathrm{CH}_{2}\right) 122.9(\mathrm{CH}) 127.0(\mathrm{CH}) 127.6(\mathrm{CH}) 127.8$ $(\mathrm{CH}) 128.1(\mathrm{CH}) 128.5(2 \times \mathrm{CH}) 129.28(\mathrm{CH}) 129.34(\mathrm{CH}) 130.2(\mathrm{CH})$ $133.6(\mathrm{CH}) 136.2$ (C) 136.4 (C) 140.0 (C) 145.2 (C) 145.9 (CH) 156.2

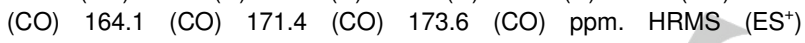
$\mathrm{C}_{43} \mathrm{H}_{52} \mathrm{~N}_{8} \mathrm{O}_{7} \mathrm{NaS}_{2}\left(\mathrm{MNa}^{+}\right)$calcd. 879.3298; found 879.3275. [ []$_{\mathrm{D}}=+12(\mathrm{C}$ $=0.1, \mathrm{CH}_{2} \mathrm{Cl}_{2}$ ).

(S/R)-Benzyl (1-phenylbut-3-yn-2-yl)carbamate ( \pm )-13: To a stirred solution of aldehyde $16^{[30]}(450 \mathrm{mg}, 1.59 \mathrm{mmol}, 1.0$ equiv.) and the OhiraBestmann reagent $17^{[31]}$ (421 mg, $1.91 \mathrm{mmol}, 1.2$ equiv.) in $\mathrm{MeOH}$ (10 $\mathrm{mL}$ ) was added $\mathrm{K}_{2} \mathrm{CO}_{3}(444 \mathrm{mg}, 3.21 \mathrm{mmol}, 2.0$ equiv.). A yellow colour was observed, which deepened to orange after 3 hours and the reaction was left to stir overnight at room temperature. Sat. aq. $\mathrm{NH}_{4} \mathrm{Cl}(10 \mathrm{~mL})$ was added and the layers were partitioned with EtOAc $(20 \mathrm{~mL})$. The layers were separated and the aqueous layer was extracted with EtOAc $(2 \times 20 \mathrm{~mL})$. The combined organic layers were washed with water $(20$ $\mathrm{mL})$, brine $(20 \mathrm{~mL})$, dried over $\mathrm{MgSO}_{4}$, filtered and solvent was removed in vacuo to give the crude product. Purification by column chromatography (c-Hex/EtOAc; 3:1) gave alkyne ${ }^{\star}( \pm)-\mathbf{1 3}$ as a white waxy solid (343 mg, 77\%). *Mixture of enantiomers. For enantiopure synthesis, see reference 24. HPLC Analysis (Chiralcel OJ-H column) Heptane/Ethanol; 90:10 (1.0 mL/min): $t_{r}$ major $(S)-\mathbf{1 3}=33.3 \mathrm{~min}, t_{r}$ minor $(R)-\mathbf{1 3}=34.5 \mathrm{~min} ; ~ 7 \%$ ee.

(R/S)-1-Phenylpentyl ((S)-1-phenylbut-3-yn-2-yl)carbamate 19. Data: M.p. $=54-58{ }^{\circ} \mathrm{C} . \mathrm{R}_{f}=0.5$ (c-Hex/EtOAc; 3:1). IR (film): $v_{\max }=3306,3032$, 2956, 2933, 2862, 1707, 1496, 1454, 1381, 1335, 1282, 1244, 1136, 1032, 756, $698 \mathrm{~cm}^{-1} .{ }^{1} \mathrm{H}$ NMR $\left(400 \mathrm{MHz}, \mathrm{CDCl}_{3}\right): \delta=0.87$ (app. q, 3H, $\left.\mathrm{CH}_{3}\right)$ 1.15-1.38 (m, 4H, $\left.\mathrm{CH}_{2}\right) 1.68-1.80\left(\mathrm{~m}, 1 \mathrm{H}, \mathrm{CH}_{2}\right)$ 1.82-1.94 $(\mathrm{m}, 1 \mathrm{H}$, $\left.\mathrm{CH}_{2}\right) 2.26(\mathrm{~s}(\mathrm{br}), 0.5 \mathrm{H}, \mathrm{CH}) 2.30(\mathrm{~d}, J=2.5 \mathrm{~Hz}, 0.5 \mathrm{H}, \mathrm{CH}) 2.85-3.07(\mathrm{~m}$, $\left.2 \mathrm{H}, \mathrm{CH}_{2}\right)$ 4.65-4.74 (m, 1H, CH) $4.87(\mathrm{~s}(\mathrm{br}), 1 \mathrm{H}, \mathrm{NH}) 5.62(\mathrm{t}, J=7.0 \mathrm{~Hz}$, $1 \mathrm{H}, \mathrm{CH})$ 7.13-7.38 (m, 10H, ArH) ppm. ${ }^{13} \mathrm{C} \mathrm{NMR}\left(100 \mathrm{MHz}, \mathrm{CDCl}_{3}\right): \delta=$ $13.9\left(\mathrm{CH}_{3}\right) 14.0\left(\mathrm{CH}_{3}\right) 22.4\left(\mathrm{CH}_{2}\right) 27.60\left(\mathrm{CH}_{2}\right) 27.62\left(\mathrm{CH}_{2}\right) 36.19\left(\mathrm{CH}_{2}\right)$ $36.22\left(\mathrm{CH}_{2}\right) 41.2\left(\mathrm{CH}_{2}\right) 41.5\left(\mathrm{CH}_{2}\right) 44.2(\mathrm{CH}) 44.3(\mathrm{CH}) 77.1(\mathrm{CH}) 77.51$ $(\mathrm{CH}) 77.52(\mathrm{CH}) 82.37$ (C) $82.43(\mathrm{C}) 126.35(\mathrm{CH}) 126.40(\mathrm{CH}) 126.93$
$(\mathrm{CH}) 126.97(\mathrm{CH}) 127.72(\mathrm{CH}) 127.76(\mathrm{CH}) 128.27(\mathrm{CH}) 128.31(\mathrm{CH})$ $128.36(\mathrm{CH}) 128.37(\mathrm{CH}) 129.8(\mathrm{CH}) 136.0$ (C) 136.1 (C) 141.0 (C) 141.1 (C) 154.8 (CO) ppm. (Note: ${ }^{13} \mathrm{C}$ NMR spectrum complicated due to mixture of diastereomers). HRMS (ES ${ }^{+} \mathrm{C}_{22} \mathrm{H}_{25} \mathrm{NO}_{2} \mathrm{Na}\left(\mathrm{MNa}^{+}\right)$calcd. 358.1783; found 358.1782. [ $\alpha]_{\mathrm{D}}=-6\left(c=0.1, \mathrm{CH}_{2} \mathrm{Cl}_{2}\right)$. Anal. calcd. $\mathrm{C}_{22} \mathrm{H}_{25} \mathrm{NO}_{2}$ : C, 78.77; H, 7.51; N, 4.18; found C, 78.61; H, 7.45; N, 4.14.

\section{(S)-tert-Butyl}

\{5-azido-6-[methoxy(methyl)amino]-6oxohexyl\}carbamate 14: Amine ${ }^{[34]} 20$ (105 mg, $0.36 \mathrm{mmol}, 1.0$ equiv.) was stirred in $\mathrm{MeOH}(4 \mathrm{~mL})$ with imidazole-1-sulfonyl azide hydrochloride ${ }^{[35]} 21$ (85 mg, $0.41 \mathrm{mmol}, 1.1$ equiv.) and $\mathrm{CuSO}_{4} \cdot 5 \mathrm{H}_{2} \mathrm{O}(1$ $\mathrm{mg}, 0.004 \mathrm{mmol}, 0.01$ equiv.) $\mathrm{K}_{2} \mathrm{CO}_{3}(57 \mathrm{mg}, 0.41 \mathrm{mmol}, 1.1$ equiv.) was added and the suspension was stirred at room temperature. The reaction was monitored by TLC and the amine starting material was completely consumed after 4 hours. The reaction mixture was concentrated and water $(5 \mathrm{~mL})$ was added to the flask. The aqueous layer was extracted with EtOAc $(3 \times 10 \mathrm{~mL})$. The combined organic layers were washed with brine $(10 \mathrm{~mL})$, dried over $\mathrm{MgSO}_{4}$, filtered and solvent was removed in vacuo to give the crude product. Purification by column chromatography (c-Hex/EtOAc; 5:2) gave azide $\mathbf{1 4}$ as a pale yellow liquid (96 mg, 84\%). $\mathrm{R}_{f}=0.4$ (c-Hex/EtOAc; 1:1). IR (film): $\mathrm{v}_{\max }=2976,2937,2866,2104$, $1693,1668,1520,1458,1391,1366,1249,1170,995 \mathrm{~cm}^{-1} .{ }^{1} \mathrm{H}$ NMR $\left(400 \mathrm{MHz}, \mathrm{CDCl}_{3}\right): \delta=1.24-1.72\left(\mathrm{~m}, 13 \mathrm{H}, \mathrm{CH}_{3}+\mathrm{CH}_{2}\right)$ 1.78-1.92 (m, $2 \mathrm{H}$, $\left.\mathrm{CH}_{2}\right)$ 3.08-3.18 (m, 2H, CH 2$) 3.23\left(\mathrm{~s}, 3 \mathrm{H}, \mathrm{CH}_{3}\right) 3.73\left(\mathrm{~s}, 3 \mathrm{H}, \mathrm{CH}_{3}\right) 4.03(\mathrm{t}$, $J=7.0 \mathrm{~Hz}, 1 \mathrm{H}, \mathrm{CH}) 4.64(\mathrm{~s}(\mathrm{br}), 1 \mathrm{H}, \mathrm{NH}) \mathrm{ppm} .{ }^{13} \mathrm{C} \mathrm{NMR}(100 \mathrm{MHz}$, $\left.\mathrm{CDCl}_{3}\right): \delta=23.2\left(\mathrm{CH}_{2}\right) 28.4\left(\mathrm{CH}_{3}\right) 29.6\left(\mathrm{CH}_{2}\right) 30.3\left(\mathrm{CH}_{2}\right) 32.2\left(\mathrm{CH}_{3}\right) 40.2$ $\left(\mathrm{CH}_{2}\right) 57.9(\mathrm{CH}) 61.7\left(\mathrm{CH}_{3}\right) 79.1$ (C) 156.0 (CO) 170.9 (CO) ppm. HRMS $\left(\mathrm{ES}^{+}\right) \mathrm{C}_{13} \mathrm{H}_{25} \mathrm{~N}_{5} \mathrm{O}_{4} \mathrm{Na}\left(\mathrm{MNa}^{+}\right)$calcd. 338.1804; found 338.1791. $[\alpha]_{\mathrm{D}}=+16$ $\left(c=0.1, \mathrm{CH}_{2} \mathrm{Cl}_{2}\right.$ ).

Benzyl \{(S)-2-phenyl-1-[1-((S)-3,13,13-trimethyl-4,11-dioxo-2,12dioxa-3,10-diazatetradecan-5-yl)-1 H-1,2,3-triazol-4-

yl]ethyl\}carbamate 22: Azide $14(130 \mathrm{mg}, 0.41 \mathrm{mmol}, 1.0$ equiv.) and alkyne ${ }^{[24]} 13$ (115 mg, $0.41 \mathrm{mmol}, 1.0$ equiv.) were stirred in $\mathrm{Me}_{2} \mathrm{CO} / \mathrm{H}_{2} \mathrm{O}$; $1: 1(5 \mathrm{~mL}) . \mathrm{CuSO}_{4} \cdot 5 \mathrm{H}_{2} \mathrm{O}(10 \mathrm{mg}, 0.04 \mathrm{mmol}, 0.10$ equiv.) and sodium ascorbate ( $25 \mathrm{mg}, 0.13 \mathrm{mmol}, 0.30$ equiv.) were added to the flask and the reaction mixture was stirred at room temperature for 48 hours. The crude mixture was extracted with EtOAc $(3 \times 20 \mathrm{~mL})$ and the combined organic layers were washed with brine $(10 \mathrm{~mL})$ dried over $\mathrm{MgSO}_{4}$, filtered and solvent was removed in vacuo. Purification by column chromatography (c-Hex/EtOAc; $1: 1)$ gave triazole 22 as a white solid (207 mg, 84\%). M.p. $=48-51{ }^{\circ} \mathrm{C} . \mathrm{R}_{f}=0.3$ (c-Hex/EtOAc; 1:2). IR (film): $v_{\max }=3322,3065,3030,2975,2933,2866,1708,1526,1455,1392$, $1366,1250,1172,1044,740 \mathrm{~cm}^{-1} .{ }^{1} \mathrm{H}$ NMR $\left(400 \mathrm{MHz}, \mathrm{CDCl}_{3}\right): \delta=1.05-$ $1.36\left(\mathrm{~m}, 2 \mathrm{H}, \mathrm{CH}_{2}\right)$ 1.38-1.53 (m, 11 $\left.\mathrm{H}, \mathrm{CH}_{3}+\mathrm{CH}_{2}\right) 1.86-1.98\left(\mathrm{~m}, 1 \mathrm{H}, \mathrm{CH}_{2}\right)$ 1.99-2.14 (m, 1H, CH $)_{2}$ 2.99-3.10 (m, 2H, CH $)_{2}$ 3.13-3.24 (m, 4H, $\mathrm{CH}_{2}+$ $\left.\mathrm{CH}_{3}\right) 3.29$ (dd, $\left.J=13.5,7.0 \mathrm{~Hz}, 1 \mathrm{H}, \mathrm{CH}_{2}\right) 3.68\left(\mathrm{~s}, 3 \mathrm{H}, \mathrm{CH}_{3}\right) 4.50(\mathrm{~s}(\mathrm{br})$, $1 \mathrm{H}, \mathrm{NH}) 5.05\left(\mathrm{~d}, J=12.5 \mathrm{~Hz}, 1 \mathrm{H}, \mathrm{CH}_{2}\right) 5.09\left(\mathrm{~d}, J=12.5 \mathrm{~Hz}, 1 \mathrm{H}, \mathrm{CH}_{2}\right)$ 5.19 (app. q, $J=7.5 \mathrm{~Hz}, 1 \mathrm{H}, \mathrm{CH}) 5.46$ (d, $J=7.0 \mathrm{~Hz}, 1 \mathrm{H}, \mathrm{NH}$ ) 5.80 (t, $J=$ $7.5 \mathrm{~Hz}, 1 \mathrm{H}, \mathrm{CH}) 7.07(\mathrm{~d}, J=7.0 \mathrm{~Hz}, 2 \mathrm{H}, \mathrm{ArH}) 7.15-7.25(\mathrm{~m}, 3 \mathrm{H}, \mathrm{ArH})$ 7.27-7.38 (m, 5H, ArH) $7.50(\mathrm{~s}, 1 \mathrm{H}, \mathrm{ArH}) \mathrm{ppm} .{ }^{13} \mathrm{C}$ NMR $(100 \mathrm{MHz}$, $\left.\mathrm{CDCl}_{3}\right): \delta=22.6\left(\mathrm{CH}_{2}\right) 28.4\left(\mathrm{CH}_{3}\right) 29.3\left(\mathrm{CH}_{2}\right) 32.2\left(\mathrm{CH}_{3}\right) 32.4\left(\mathrm{CH}_{2}\right) 40.0$ $\left(\mathrm{CH}_{2}\right) 41.5\left(\mathrm{CH}_{2}\right) 49.1(\mathrm{CH}) 58.7(\mathrm{CH}) 61.9\left(\mathrm{CH}_{3}\right) 66.7\left(\mathrm{CH}_{2}\right) 79.2(\mathrm{C})$ $120.5(\mathrm{CH}) 126.6(\mathrm{CH}) 128.0(\mathrm{CH}) 128.1(\mathrm{CH}) 128.3(\mathrm{CH}) 128.5(\mathrm{CH})$ 129.6 (CH) 136.5 (C) 137.0 (C) 147.8 (C) 155.6 (CO) 155.9 (CO) 168.4 (CO) ppm. HRMS (ES $\left.{ }^{+}\right) \mathrm{C}_{31} \mathrm{H}_{42} \mathrm{~N}_{6} \mathrm{O}_{6} \mathrm{Na}\left(\mathrm{MNa}^{+}\right)$calcd. 617.3064; found 617.3060. $[\alpha]_{D}=-14\left(c=0.1, \mathrm{CH}_{2} \mathrm{Cl}_{2}\right)$.

Benzyl \{(S)-1-[1-((S)-6-((tert-butoxycarbonyl)amino)-1-oxohexan-2yl)-1 H-1,2,3-triazol-4-yl]-2-phenylethyl\}carbamate 23: At $-78{ }^{\circ} \mathrm{C}$, under nitrogen, to a vigorously stirred solution of $\mathrm{LiAlH}_{4}(25 \mathrm{mg}, 0.66$ mmol, 4.1 equiv.) in THF (2.5 mL) was added Weinreb amide $22(97 \mathrm{mg}$, $0.16 \mathrm{mmol}, 1.0$ equiv.) in THF $(2.5 \mathrm{~mL})$ and the reaction mixture was stirred for 5 minutes. A $1 \mathrm{M}$ solution of $\mathrm{KHSO}_{4}(\sim 2 \mathrm{~mL})$ was cautiously 
added dropwise at $-78{ }^{\circ} \mathrm{C}$. EtOAc $(10 \mathrm{~mL})$ was then added and the solution was allowed to warm to room temperature with vigorous stirring. The organic layer was separated and the aqueous layer was extracted with EtOAc $(3 \times 10 \mathrm{~mL})$. The combined organic layers were successively washed with $0.5 \mathrm{M} \mathrm{HCl}(2 \times 10 \mathrm{~mL})$, saturated $\mathrm{NaHCO}_{3}(2 \times 10 \mathrm{~mL})$, brine $(10 \mathrm{~mL})$, dried over $\mathrm{MgSO}_{4}$ and filtered. Solvent was removed in vacuo to give aldehyde 23 as an off white, waxy solid and was used without further purification (84 mg, 96\%). Note: this benzylic aldehyde was found to be unstable and prone to epimerisation and hydrate formation. It was also found to be sensitive to silica gel column chromatography. Therefore, it was used immediately for the subsequent Horner-Wadsworth-Emmons olefination. M.p. $=54-58{ }^{\circ} \mathrm{C} . \mathrm{R}_{f}=0.1$ (cHex/EtOAc; 1:2). IR (film): $v_{\max }=3308,3063,3031,2974,2932,2865$, 1693, 1522, 1455, 1392, 1366, 1250, 1169, 1042, 739, $700 \mathrm{~cm}^{-1} .{ }^{1} \mathrm{H}$ $\operatorname{NMR}\left(400 \mathrm{MHz}, \mathrm{CDCl}_{3}\right): \delta=1.08-2.03\left(\mathrm{~m}, 14 \mathrm{H}, \mathrm{CH}_{3}+\mathrm{CH}_{2}\right) 2.12-2.25(\mathrm{~m}$ $\left.1 \mathrm{H}, \mathrm{CH}_{2}\right)$ 2.91-3.10 (m, 2H, $\left.\mathrm{CH}_{2}\right)$ 3.11-3.22 (m, 1H, $\left.\mathrm{CH}_{2}\right)$ 3.24-3.41 (m, $\left.1 \mathrm{H}, \mathrm{CH}_{2}\right) 4.53(\mathrm{~s}(\mathrm{br}), 1 \mathrm{H}, \mathrm{NH}) 4.99-5.19\left(\mathrm{~m}, 4 \mathrm{H}, \mathrm{CH}+\mathrm{CH}_{2}\right) 5.64(\mathrm{~d}, J=$ $5.5 \mathrm{~Hz}, 1 \mathrm{H}, \mathrm{NH}) 7.05(\mathrm{~d}, J=6.5 \mathrm{~Hz}, 2 \mathrm{H}, \mathrm{ArH}) 7.12(\mathrm{~s}, 1 \mathrm{H}, \mathrm{ArH}) 7.15-7.25$ $(\mathrm{m}, 4 \mathrm{H}, \mathrm{ArH}) 7.27-7.38(\mathrm{~m}, 4 \mathrm{H}, \mathrm{ArH}) 9.61(\mathrm{~s}, 1 \mathrm{H}, \mathrm{CHO}) \mathrm{ppm} .{ }^{13} \mathrm{C} \mathrm{NMR}$ $\left(100 \mathrm{MHz}, \mathrm{CDCl}_{3}\right): \delta=22.5\left(\mathrm{CH}_{2}\right) 28.4\left(\mathrm{CH}_{3}\right) 29.2\left(\mathrm{CH}_{2}\right) 29.3\left(\mathrm{CH}_{2}\right) 39.9$ $\left(\mathrm{CH}_{2}\right) 41.7\left(\mathrm{CH}_{2}\right) 49.3(\mathrm{CH}) 66.8\left(\mathrm{CH}_{2}\right) 68.4(\mathrm{CH}) 79.4(\mathrm{C}) 121.4(\mathrm{CH})$ $128.0(\mathrm{CH}) 128.1(\mathrm{CH}) 128.3(\mathrm{CH}) 128.4(\mathrm{CH}) 128.5(\mathrm{CH}) 129.5(\mathrm{CH})$ 136.3 (C) 137.0 (C) 147.8 (C) 155.7 (CO) 156.0 (CO) 194.7 (CHO) ppm. HRMS $\left(\mathrm{ES}^{+}\right) \mathrm{C}_{29} \mathrm{H}_{37} \mathrm{~N}_{5} \mathrm{O}_{5} \mathrm{Na}\left(\mathrm{MNa}^{+}\right)$calcd. 558.2692; found 558.2682. $[\alpha]_{\mathrm{D}}=-15\left(c=0.1, \mathrm{CH}_{2} \mathrm{Cl}_{2}\right)$

Benzyl

$(S, E / Z)-\{1-[1-(7-(($ tert-butoxycarbonyl)amino $)-1-$ (phenylsulfonyl)hept-2-en-3-yl)-1H-1,2,3-triazol-4-yl]-2-

phenylethyl\}carbamate 24: At $0{ }^{\circ} \mathrm{C}$, under nitrogen, to a stirred solution of $60 \% \mathrm{NaH}$ in mineral oil ( $5 \mathrm{mg}, 0.13 \mathrm{mmol}, 1.1$ equiv.) in THF ( $2 \mathrm{~mL})$ was added phosphonate 15 ( $41 \mathrm{mg}, 0.14 \mathrm{mmol}, 1.2$ equiv.) as a solution in THF $(1 \mathrm{~mL})$. The reaction mixture was stirred for 10 minutes at $0{ }^{\circ} \mathrm{C}$ before aldehyde 23 (62 mg, $0.12 \mathrm{mmol}, 1.0$ equiv.) was added as a solution in THF (1 mL). The reaction mixture was left to stir overnight, gradually warming to room temperature. The reaction mixture was quenched with water $(5 \mathrm{~mL})$ and extracted with EtOAc $(3 \times 10 \mathrm{~mL})$. The combined organic layers were washed with brine $(10 \mathrm{~mL})$, dried over $\mathrm{MgSO}_{4}$, filtered and solvent was removed in vacuo to give the crude product. Purification by column chromatography ( $c$-Hex/EtOAc; 1:1) gave allyl sulfone $\mathbf{2 4}$ as a white solid (55 mg, 71\%). Inseparable mixture of $E / Z$ (1:1) isomers. M.p. $=79-85^{\circ} \mathrm{C} . \mathrm{R}_{f}=0.4$ (c-Hex/EtOAc; $\left.1: 2\right) . \mathrm{IR}\left(\right.$ film) $: \mathrm{v}_{\max }$ = 3353, 2976, 2930, 1702, 1521, 1447, 1308, 1248, 1167, 1150, 1085 , 1040, 738, $701 \mathrm{~cm}^{-1}$. ${ }^{1} \mathrm{H}$ NMR $\left(500 \mathrm{MHz}, \mathrm{CDCl}_{3}\right): \delta=1.10-1.41(\mathrm{~m}, 4 \mathrm{H}$, $\left.\mathrm{CH}_{2}\right)$ 1.42, $1.43\left(\mathrm{~s}, 9 \mathrm{H}, \mathrm{CH}_{3}\right)$ 2.42-2.52 $\left(\mathrm{m}, 2 \mathrm{H}, \mathrm{CH}_{2}\right)$ 2.96-3.07 (m, $2 \mathrm{H}$, $\left.\mathrm{CH}_{2}\right) 3.12-3.20\left(\mathrm{~m}, 1 \mathrm{H}, \mathrm{CH}_{2}\right) 3.33\left(\mathrm{dd}, J=13.0,5.0 \mathrm{~Hz}, 1 \mathrm{H}, \mathrm{CH}_{2}\right) 3.68$ (dd, $\left.J=14.5,8.0 \mathrm{~Hz}, 0.5 \mathrm{H}, \mathrm{CH}_{2}\right) 3.68\left(\mathrm{dd}, J=14.5,8.0 \mathrm{~Hz}, 0.5 \mathrm{H}, \mathrm{CH}_{2}\right.$ ) $3.98\left(\mathrm{~d}, J=8.0 \mathrm{~Hz}, 1 \mathrm{H}, \mathrm{CH}_{2}\right) 4.52(\mathrm{~s}(\mathrm{br}), 1 \mathrm{H}, \mathrm{CH}) 5.05-5.17(\mathrm{~m}, 3 \mathrm{H}, \mathrm{CH}$ $\left.+\mathrm{CH}_{2}\right) 5.53(\mathrm{~d}, J=6.5 \mathrm{~Hz}, 0.5 \mathrm{H}, \mathrm{NH}) 5.58(\mathrm{~d}, J=7.5 \mathrm{~Hz}, 0.5 \mathrm{H}, \mathrm{NH}) 5.66$ (t, $J=8.0 \mathrm{~Hz}, 0.5 \mathrm{H}, \mathrm{CH}) 5.75(\mathrm{t}, J=8.0 \mathrm{~Hz}, 0.5 \mathrm{H}, \mathrm{CH}) 6.78(\mathrm{~s}, 0.5 \mathrm{H}$, ArH) $7.03(\mathrm{~d}, J=7.0 \mathrm{~Hz}, 1 \mathrm{H}, \mathrm{ArH}) 7.06(\mathrm{~d}, J=7.0 \mathrm{~Hz}, 1 \mathrm{H}, \mathrm{ArH}) 7.17-7.25$ (m, 3.5H, ArH) 7.29-7.38 (m, 5H, ArH) $7.47(\mathrm{t}, J=7.5 \mathrm{~Hz}, 1 \mathrm{H}, \mathrm{ArH}) 7.57$ $(\mathrm{t}, J=7.5 \mathrm{~Hz}, 1 \mathrm{H}, \mathrm{ArH}) 7.61(\mathrm{~d}, J=7.5 \mathrm{~Hz}, 0.5 \mathrm{H}, \operatorname{ArH}) 7.68(\mathrm{~d}, J=7.5$ $\mathrm{Hz}, 0.5 \mathrm{H}, \mathrm{ArH}) 7.70(\mathrm{~d}, J=7.5 \mathrm{~Hz}, 1 \mathrm{H}, \mathrm{ArH}) 7.90(\mathrm{~d}, J=7.5 \mathrm{~Hz}, 1 \mathrm{H}$, ArH) ppm. ${ }^{13} \mathrm{C}$ NMR $\left(125 \mathrm{MHz}, \mathrm{CDCl}_{3}\right): \delta=23.6\left(\mathrm{CH}_{2}\right) 24.0\left(\mathrm{CH}_{2}\right) 27.9$ $\left(\mathrm{CH}_{2}\right) 35.8\left(\mathrm{CH}_{2}\right) 28.4\left(\mathrm{CH}_{3}\right) 29.0\left(\mathrm{CH}_{2}\right) 29.5\left(\mathrm{CH}_{2}\right) 39.5\left(\mathrm{CH}_{2}\right) 39.9\left(\mathrm{CH}_{2}\right)$ $41.5\left(\mathrm{CH}_{2}\right) 49.0(\mathrm{CH}) 49.1(\mathrm{CH}) 54.7\left(\mathrm{CH}_{2}\right) 55.0\left(\mathrm{CH}_{2}\right) 66.9\left(\mathrm{CH}_{2}\right) 79.3$ (C) $108.1(\mathrm{CH}) 112.6(\mathrm{CH}) 119.7(\mathrm{CH}) 121.8(\mathrm{CH}) 126.8(\mathrm{CH}) 126.9(\mathrm{CH})$ $128.0(\mathrm{CH}) 128.1(\mathrm{CH}) 128.15(\mathrm{CH}) 128.19(\mathrm{CH}) 128.3(\mathrm{CH}) 128.4(\mathrm{CH})$ $128.5(\mathrm{CH}) 128.52(\mathrm{CH}) 128.54(\mathrm{CH}) 129.3(\mathrm{CH}) 129.4(\mathrm{CH}) 129.5(\mathrm{CH})$ $134.1(\mathrm{CH}) 134.2(\mathrm{CH}) 136.3(\mathrm{C}) 136.9(\mathrm{C}) 137.0(\mathrm{C}) 138.2(\mathrm{C}) 138.3(\mathrm{C})$ 142.4 (C) 143.3 (C) 146.9 (C) 147.4 (C) 155.6 (CO) 155.7 (CO) 155.9 (CO) 156.0 (CO) ppm. Note: ${ }^{1} \mathrm{H}$ and ${ }^{13} \mathrm{C}$ NMR spectrum complicated due to mixture of geometrical isomers. HRMS $\left(\mathrm{ES}^{+}\right) \mathrm{C}_{36} \mathrm{H}_{43} \mathrm{~N}_{5} \mathrm{O}_{6} \mathrm{NaS}\left(\mathrm{MNa}^{+}\right)$ calcd. 696.2832; found 696.2828. $[\alpha]_{\mathrm{D}}=-24\left(c=0.1, \mathrm{CH}_{2} \mathrm{Cl}_{2}\right)$.
Benzyl $\{(S)-1-[1-((S, E)-7-(($ tert-butoxycarbonyl)amino $)-1-$ (phenylsulfonyl)hept-1-en-3-yl)-1 H-1,2,3-triazol-4-yl]-2-

phenylethyl\}carbamate $^{[24]}$ 5: In a procedure identical to the HWE reaction described directly above: $60 \% \mathrm{NaH}$ in mineral oil $(12 \mathrm{mg}, 0.30$ mmol, 0.9 equiv.), phosphonate 15 (104 mg, $0.36 \mathrm{mmol}, 1.1$ equiv.), aldehyde 23 (173 mg, $0.32 \mathrm{mmol}, 1.0$ equiv.) and THF (10 mL total). After aqueous workup, purification by column chromatography ( $c$ Hex/EtOAc; 1:1) gave vinyl sulfone 5 as a white powdery solid (98 mg, $48 \%$ based on $\mathrm{NaH}$ ). $\mathrm{R}_{f}=0.4$ (c-Hex/EtOAc; $\left.1: 2\right)$. M.p. $=149-152{ }^{\circ} \mathrm{C}$ (decomp.); Lit. ${ }^{[24]}$ M.p. $=156-159{ }^{\circ} \mathrm{C} .[\alpha]_{\mathrm{D}}=+20\left(c=0.1, \mathrm{CH}_{2} \mathrm{Cl}_{2}\right)$; Lit. ${ }^{[24]}$ $[\alpha]_{\mathrm{D}}=+21\left(c=1.0, \mathrm{CHCl}_{3}\right)$. Data are consistent with that reported in the literature. ${ }^{[24]}$

(S)-(9H-Fluoren-9-yl)methyl tert-butyl (6-oxohexane-1,5diyl)dicarbamate ${ }^{[39]} 27$ : Under nitrogen, at $-78{ }^{\circ} \mathrm{C}$, to a vigorously stirred solution of $\mathrm{LiAlH}_{4}(0.95 \mathrm{~g}, 25 \mathrm{mmol}, 5.0$ equiv.) in THF (30 mL) was added Weinreb amide $26^{[38]}$ ( $2.55 \mathrm{~g}, 5.0 \mathrm{mmol}, 1.0$ equiv.) as a solution in THF $(20 \mathrm{~mL})$ and the reaction mixture was stirred for 5 minutes. Cautiously, $1 \mathrm{M} \mathrm{KHSO}_{4}(15 \mathrm{~mL})$ was added dropwise to the flask to quench the reaction. Water $(20 \mathrm{~mL})$ was then added followed by EtOAc $(50 \mathrm{~mL})$ and the solution was warmed to room temperature stirring vigorously. The contents of the flask were transferred to a separating funnel and the layers were separated. The aqueous layer was extracted with EtOAc $(3 \times 50 \mathrm{~mL})$. The combined organic layers were washed with $1 \mathrm{M} \mathrm{HCl}(2 \times 30 \mathrm{~mL})$, sat. aq. $\mathrm{NaHCO}_{3}(2 \times 30 \mathrm{~mL})$, water $(30 \mathrm{~mL})$ and brine $(30 \mathrm{~mL})$. The organic layer was dried over $\mathrm{MgSO}_{4}$, filtered and solvent was removed in vacuo to give aldehyde $\mathbf{2 7}$ as a white solid which was used without further purification $(2.17 \mathrm{~g},>95 \%)$. M.p. $=48-54{ }^{\circ} \mathrm{C}$; Lit. ${ }^{[39]} 114-116{ }^{\circ} \mathrm{C} . \mathrm{R}_{f}=0.6$ (c-Hex/EtOAc; 1:2). IR (film): $\mathrm{v}_{\max }=3051$, 2974, 2936, 1693, 1518, 1451, 1403, 1366, 1251, 1168, 760, $737 \mathrm{~cm}^{-1}$. ${ }^{1} \mathrm{H} \mathrm{NMR}\left(400 \mathrm{MHz}, \mathrm{CDCl}_{3}\right): \delta=1.27-1.72\left(\mathrm{~m}, 15 \mathrm{H}, \mathrm{CH}_{3}+\mathrm{CH}_{2}\right) 3.01-3.18$ $\left(\mathrm{m}, 2 \mathrm{H}, \mathrm{CH}_{2}\right) 4.22$ (t, $\left.J=7.0 \mathrm{~Hz}, 1 \mathrm{H}, \mathrm{CH}\right) 4.28$ (app. q, $J=6.0 \mathrm{~Hz}, 1 \mathrm{H}$, $\mathrm{CH})$ 4.36-4.49 (m, 2H, CH 2$) 4.57(\mathrm{~s}(\mathrm{br}), 1 \mathrm{H}, \mathrm{NH}) 5.49(\mathrm{~s}(\mathrm{br}), 1 \mathrm{H}, \mathrm{NH})$ $7.32(\mathrm{t}, J=7.5 \mathrm{~Hz}, 2 \mathrm{H}$, ArH) $7.40(\mathrm{t}, J=7.5 \mathrm{~Hz}, 2 \mathrm{H}, \mathrm{ArH}) 7.61(\mathrm{~d}, J=7.5$ $\mathrm{Hz}, 2 \mathrm{H}, \mathrm{ArH}) 7.77$ (d, $J=7.5 \mathrm{~Hz}, 2 \mathrm{H}, \mathrm{ArH}) 9.57$ (s, $1 \mathrm{H}, \mathrm{CHO}) \mathrm{ppm} .{ }^{13} \mathrm{C}$ NMR $\left(100 \mathrm{MHz}, \mathrm{CDCl}_{3}\right): \delta=22.1\left(\mathrm{CH}_{2}\right) 28.4\left(\mathrm{CH}_{3}\right) 28.5\left(\mathrm{CH}_{2}\right) 29.8\left(\mathrm{CH}_{2}\right)$ $39.8\left(\mathrm{CH}_{2}\right) 47.2(\mathrm{CH}) 60.1(\mathrm{CH}) 67.0\left(\mathrm{CH}_{2}\right) 79.3(\mathrm{C}) 120.0(\mathrm{CH}) 125.0$ $(\mathrm{CH}) 127.1(\mathrm{CH}) 127.7(\mathrm{CH}) 141.3(\mathrm{C}) 143.7(\mathrm{C}) 156.2(2 \times \mathrm{CO}) 199.3$ (CHO) ppm. HRMS (ES $)^{+} \mathrm{C}_{26} \mathrm{H}_{33} \mathrm{~N}_{2} \mathrm{O}_{5}\left(\mathrm{MH}^{+}\right)$calcd. 453.2389; found 453.2371. $[\alpha]_{\mathrm{D}}=+12\left(c=0.1, \mathrm{CH}_{2} \mathrm{Cl}_{2}\right)$; Lit. $^{[39]}[\alpha]_{\mathrm{D}}=+11.3(c=1.0$, $\left.\mathrm{CHCl}_{3}\right)$. Data are consistent with that reported in the literature. ${ }^{[39]}$

(S,E)-(9H-Fluoren-9-yl)methyl tert-butyl [7-(phenylsulfonyl)hept-6ene-1,5-diyl]dicarbamate 28: At $0{ }^{\circ} \mathrm{C}$, under nitrogen, to a stirred solution of $60 \% \mathrm{NaH}$ in mineral oil ( $9 \mathrm{mg}, 0.22 \mathrm{mmol}, 1.5$ equiv.) in THF ( $1 \mathrm{~mL}$ ) was added phosphonate 15 (93 $\mathrm{mg}, 0.32 \mathrm{mmol}, 2.1$ equiv.) as a solution in THF (1 mL) and the reaction mixture was stirred for 30 minutes. Aldehyde $27^{[39]}$ (70 mg, $0.15 \mathrm{mmol}, 1.0$ equiv.) was added as a solution in THF $(1 \mathrm{~mL})$ and the reaction mixture was stirred overnight warming gradually to room temperature. The reaction mixture was quenched with water $(3 \mathrm{~mL})$ and extracted with $\mathrm{CH}_{2} \mathrm{Cl}_{2}(3 \times 10 \mathrm{~mL})$. The combined organic layers were washed with brine $(10 \mathrm{~mL})$, dried over $\mathrm{MgSO}_{4}$, filtered and solvent was removed in vacuo to give the crude product. Purification by column chromatography (c-Hex/EtOAc; $1: 1)$ gave vinyl sulfone 28 as a white solid (54 mg, 59\%). M.p. $=114-117^{\circ} \mathrm{C} . \mathrm{R}_{f}=$ 0.5 (c-Hex/EtOAc; 1:1). ${ }^{1} \mathrm{H}$ NMR (400 MHz, $\left.\mathrm{CDCl}_{3}\right): \delta=1.26-1.73(\mathrm{~m}$, $\left.15 \mathrm{H}, \mathrm{CH}_{3}+\mathrm{CH}_{2}\right)$ 3.01-3.19 (m, 2H, $\left.\mathrm{CH}_{2}\right)$ 4.12-4.18 (m, $\left.1 \mathrm{H}, \mathrm{CH}\right)$ 4.32$4.47\left(\mathrm{~m}, 3 \mathrm{H}, \mathrm{CH}+\mathrm{CH}_{2}\right) 4.56(\mathrm{~s}(\mathrm{br}), 1 \mathrm{H}, \mathrm{NH}) 4.99(\mathrm{~d}, J=6.0 \mathrm{~Hz}, 1 \mathrm{H}, \mathrm{NH})$ $6.37(\mathrm{~d}, J=15.0 \mathrm{~Hz}, 1 \mathrm{H}, \mathrm{CH}) 6.88(\mathrm{dd}, J=15.0,5.0 \mathrm{~Hz}, 1 \mathrm{H}, \mathrm{CH}) 7.27-$ $7.33(\mathrm{~m}, 2 \mathrm{H}, \mathrm{ArH}) 7.39(\mathrm{t}, J=7.5 \mathrm{~Hz}, 2 \mathrm{H}, \mathrm{ArH}) 7.46-7.62(\mathrm{~m}, 5 \mathrm{H}, \mathrm{ArH})$ $7.75(\mathrm{~d}, J=7.5 \mathrm{~Hz}, 2 \mathrm{H}, \mathrm{ArH}) 7.85(\mathrm{~d}, J=7.5 \mathrm{~Hz}, 2 \mathrm{H}, \mathrm{ArH}) \mathrm{ppm} .{ }^{13} \mathrm{C}$ NMR $\left(100 \mathrm{MHz}, \mathrm{CDCl}_{3}\right): \delta=22.6\left(\mathrm{CH}_{2}\right) 28.4\left(\mathrm{CH}_{3}\right) 29.7\left(\mathrm{CH}_{2}\right) 33.5\left(\mathrm{CH}_{2}\right) 39.8$ $\left(\mathrm{CH}_{2}\right) 47.2(\mathrm{CH}) 51.4(\mathrm{CH}) 66.7\left(\mathrm{CH}_{2}\right) 79.3(\mathrm{C}) 120.0(\mathrm{CH}) 124.9(\mathrm{CH})$ $127.1(\mathrm{CH}) 127.6(\mathrm{CH}) 127.8(\mathrm{CH}) 129.3(\mathrm{CH}) 130.5(\mathrm{CH}) 133.5(\mathrm{CH})$ 
140.1 (C) 141.3 (C) 143.7 (C) 146.1 (CH) 155.7 (CO) 156.2 (CO) ppm HRMS (ES $\left.{ }^{+}\right) \mathrm{C}_{33} \mathrm{H}_{38} \mathrm{~N}_{2} \mathrm{O}_{6} \mathrm{NaS}\left(\mathrm{MNa}^{+}\right)$calcd. 613.2348; found 613.2371. $[\alpha]_{\mathrm{D}}=-4\left(c=0.1, \mathrm{CH}_{2} \mathrm{Cl}_{2}\right)$. Anal. calcd. $\mathrm{C}_{33} \mathrm{H}_{38} \mathrm{~N}_{2} \mathrm{O}_{6} \mathrm{~S}: \mathrm{C}, 67.10 ; \mathrm{H}, 6.48$; N, 4.74; found C, 66.71; H, 6.37; N, 4.62 .

\section{(S,E)-tert-Buty}

[5-azido-7-(phenylsulfonyl)hept-6-en-1yl]carbamate ${ }^{[24]}$ 25: Fmoc-protected vinyl sulfone 28 (597 mg, 1.01 mmol, 1.0 equiv.) was stirred in a $50 \%$ solution of diethylamine in acetonitrile $(5 \mathrm{~mL})$. The reaction was monitored by TLC. After reaction completion ( 1 hour) solvent was removed in vacuo to give the crude product. $\mathrm{R}_{f}=0.4\left(\mathrm{CH}_{2} \mathrm{Cl}_{2} / \mathrm{MeOH} ; 10: 1\right)$. HRMS $\left(\mathrm{ES}^{+}\right) \mathrm{C}_{18} \mathrm{H}_{28} \mathrm{~N}_{2} \mathrm{O}_{4} \mathrm{NaS}$ $\left(\mathrm{MNa}^{+}\right)$calcd. 391.1667; found 391.1692. This crude product was used immediately for the diazotransfer reaction. To a methanol solution $(3 \mathrm{~mL})$ of this crude deprotected amine was added imidazole-1-sulfonyl azide hydrochloride $21^{[35]}$ (635 mg, $3.03 \mathrm{mmol}, 3.0$ equiv.) and $\mathrm{CuSO}_{4} \cdot 5 \mathrm{H}_{2} \mathrm{O}$ (10 mg, $0.04 \mathrm{mmol}, 0.05$ equiv.). $\mathrm{K}_{2} \mathrm{CO}_{3}(410 \mathrm{mg}, 2.97 \mathrm{mmol}, 2.9$ equiv.) was added to the flask and the reaction mixture was stirred overnight at room temperature. The reaction mixture was concentrated in vacuo and the residue was diluted with water $(10 \mathrm{~mL})$ and extracted with EtOAc $(3 \times$ $20 \mathrm{~mL})$. The combined organic layers were washed with brine $(10 \mathrm{~mL})$, dried over $\mathrm{MgSO}_{4}$, filtered and solvent was removed in vacuo to the crude product. Purification by column chromatography (c-Hex/EtOAc; 2:1) gave allylic azide $\mathbf{2 7}$ as a clear pale yellow oil $(137 \mathrm{mg}, 34 \%$ over 2 steps). $\mathrm{R}_{f}=0.5\left(c\right.$-Hex/EtOAc 1:1). $[\alpha]_{\mathrm{D}}=+16\left(c=0.1, \mathrm{CH}_{2} \mathrm{Cl}_{2}\right) ;$ Lit. $^{[24]}$ $[\alpha]_{\mathrm{D}}=+25\left(c=2.0, \mathrm{CHCl}_{3}\right)$. Data are consistent with that reported in the literature. ${ }^{[24]}$

\section{Benzyl \\ $\{(S)-1-[1-((S, E)-7-(($ tert-butoxycarbonyl)amino)-1-} (phenylsulfonyl)hept-1-en-3-yl)-1H-1,2,3-triazol-4-yl]-2-

phenylethyl\}carbamate ${ }^{[24]}$ 5: Alternative synthesis: To a stirred solution of allylic azide 25 (17 mg, $0.04 \mathrm{mmol}, 1.0$ equiv.) and alkyne $13(15 \mathrm{mg}$, $0.05 \mathrm{mmol}, 1.2$ equiv.) in a mixture of $\mathrm{Me}_{2} \mathrm{CO} / \mathrm{H}_{2} \mathrm{O} ; 1: 1(2 \mathrm{~mL}$ ) was added $\mathrm{CuSO}_{4} \cdot 5 \mathrm{H}_{2} \mathrm{O}(1 \mathrm{mg}, 0.004 \mathrm{mmol}, 0.1$ equiv.) and sodium ascorbate $(3$ $\mathrm{mg}, 0.015 \mathrm{mmol}, 0.4$ equiv.). Stirring was continued for 48 hours at room temperature after which time the reaction mixture was diluted with water $(2 \mathrm{~mL})$ and extracted with EtOAc $(3 \times 5 \mathrm{~mL})$. The combined organic layers were washed with brine $(5 \mathrm{~mL})$, dried over $\mathrm{MgSO}_{4}$, filtered and solvent was removed in vacuo to give the crude product. Purification by column chromatography (c-Hex/EtOAc; $1: 1)$ gave triazole $5^{[24]}$ as a white solid $(15 \mathrm{mg}, 52 \%)$. Data are consistent with that reported in the literature. ${ }^{[24]}$

\section{(S,E)-tert-Butyl}

[5-(4-phenyl-1 H-1,2,3-triazol-1-yl)-7(phenylsulfonyl)hept-6-en-1-yl]carbamate 29: As per general procedure: allylic azide $25^{[24]}(20 \mathrm{mg}, 0.05 \mathrm{mmol}, 1.0$ equiv.), phenylacetylene (11 $\mathrm{LL}, 0.1 \mathrm{mmol}, 2.0$ equiv.), $\mathrm{Me}_{2} \mathrm{CO} / \mathrm{H}_{2} \mathrm{O} ; 1: 1(2 \mathrm{~mL})$, $\mathrm{CuSO}_{4} \cdot 5 \mathrm{H}_{2} \mathrm{O}(2 \mathrm{mg}, 0.008 \mathrm{mmol}, 0.2$ equiv. $)$ and sodium ascorbate $(5$ $\mathrm{mg}, 0.015 \mathrm{mmol}, 0.5$ equiv.) were stirred at room temperature for 48 hours. After aqueous workup, purification by column chromatography ( $c$ $\mathrm{Hex} / \mathrm{EtOAc}$; 1:1) gave triazole 29 as a white solid (18 mg, 71\%). M.p. = 104-107 ${ }^{\circ} \mathrm{C} . \mathrm{R}_{f}=0.4$ (c-Hex/EtOAc; 1:1). IR (film): $\mathrm{v}_{\max }=3393$, 3135, $3059,2977,2932,2865,1776,1697,1520,1448,1366,1310,1280$, $1251,1149,1086,766 \mathrm{~cm}^{-1}$. ${ }^{1} \mathrm{H}$ NMR $\left(600 \mathrm{MHz}, \mathrm{CDCl}_{3}\right): \delta=1.21-1.59$ $\left(\mathrm{m}, 13 \mathrm{H}, \mathrm{CH}_{3}+\mathrm{CH}_{2}\right)$ 2.07-2.14 $\left(\mathrm{m}, 1 \mathrm{H}, \mathrm{CH}_{2}\right)$ 2.17-2.25 $\left(\mathrm{m}, 1 \mathrm{H}, \mathrm{CH}_{2}\right)$ 3.01-3.13 (m, 2H, $\left.\mathrm{CH}_{2}\right) 4.51(\mathrm{~s}(\mathrm{br}), 1 \mathrm{H}, \mathrm{NH}) 5.30-5.35(\mathrm{~m}, 1 \mathrm{H}, \mathrm{CH}) 6.26$ (dd, $J=15.0,1.5 \mathrm{~Hz}, 1 \mathrm{H}, \mathrm{CH}) 7.15(\mathrm{dd}, J=15.0,5.5 \mathrm{~Hz}, 1 \mathrm{H}, \mathrm{CH}) 7.36(\mathrm{t}$, $J=7.5 \mathrm{~Hz}, 1 \mathrm{H}, \mathrm{ArH}) 7.44(\mathrm{t}, J=7.5 \mathrm{~Hz}, 2 \mathrm{H}, \operatorname{ArH}) 7.54(\mathrm{t}, J=8.0 \mathrm{~Hz}, 2 \mathrm{H}$, ArH) $7.64(\mathrm{t}, J=7.5 \mathrm{~Hz}, 1 \mathrm{H}, \mathrm{ArH}) 7.78(\mathrm{~s}, 1 \mathrm{H}, \mathrm{ArH}) 7.82-7.85(\mathrm{~m}, 4 \mathrm{H}$, ArH) ppm. ${ }^{13} \mathrm{C}$ NMR $\left(150 \mathrm{MHz}, \mathrm{CDCl}_{3}\right): \delta=23.0\left(\mathrm{CH}_{2}\right) 28.4\left(\mathrm{CH}_{3}\right) 29.5$ $\left(\mathrm{CH}_{2}\right) 33.7\left(\mathrm{CH}_{2}\right) 39.9\left(\mathrm{CH}_{2}\right) 61.0(\mathrm{CH}) 79.3(\mathrm{C}) 118.3(\mathrm{CH}) 125.8(\mathrm{CH})$ $127.9(\mathrm{CH}) 128.5(\mathrm{CH}) 128.9(\mathrm{CH}) 129.5(\mathrm{CH}) 130.0(\mathrm{C}) 132.9(\mathrm{CH})$ 133.9 (CH) 139.3 (C) 141.9 (CH) 148.3 (C) 156.0 (CO) ppm. HRMS (ES $)^{+} \mathrm{C}_{26} \mathrm{H}_{33} \mathrm{~N}_{4} \mathrm{O}_{4} \mathrm{~S}\left(\mathrm{MH}^{+}\right)$calcd. 497.2223; found 497.2200. $[\alpha]_{\mathrm{D}}=+71(\mathrm{c}$ $=0.1, \mathrm{CH}_{2} \mathrm{Cl}_{2}$ ).
(S,E)-tert-Butyl

[5-(4-hexyl-1H-1,2,3-triazol-1-yl)-7(phenylsulfonyl)hept-6-en-1-yl]carbamate 30: As per general procedure: allylic azide $25^{[24]}$ (20 mg, $0.05 \mathrm{mmol}, 1.0$ equiv.), $n$-octyne (15 $\mu \mathrm{L}, 0.1 \mathrm{mmol}, 2.0$ equiv.), $\mathrm{Me}_{2} \mathrm{CO} / \mathrm{H}_{2} \mathrm{O} ; 1: 1$ (2 mL), $\mathrm{CuSO}_{4} \cdot 5 \mathrm{H}_{2} \mathrm{O}(2$ $\mathrm{mg}, 0.008 \mathrm{mmol}, 0.2$ equiv.) and sodium ascorbate $(5 \mathrm{mg}, 0.015 \mathrm{mmol}$, 0.5 equiv.) were stirred at room temperature for 48 hours. After aqueous workup, purification by column chromatography (c-Hex/EtOAc; $1: 1)$ gave triazole 30 as a white solid ( $13 \mathrm{mg}, 51 \%)$. M.p. $=58-62{ }^{\circ} \mathrm{C} . \mathrm{R}_{f}=0.4(\mathrm{c}-$ Hex/EtOAc; 1:1). IR (film): $v_{\max }=3390,2930,2859,1699,1522,1447$, $1366,1281,1251,1172,1150,1087,1044,754 \mathrm{~cm}^{-1}$. ${ }^{1} \mathrm{H}$ NMR $(500 \mathrm{MHz}$, $\left.\mathrm{CDCl}_{3}\right): \delta=0.82-0.94\left(\mathrm{~m}, 3 \mathrm{H}, \mathrm{CH}_{3}\right) 1.08-1.79\left(\mathrm{~m}, 21 \mathrm{H}, \mathrm{CH}_{3}+\mathrm{CH}_{2}\right) 1.97-$ $2.19\left(\mathrm{~m}, 2 \mathrm{H}, \mathrm{CH}_{2}\right)$ 2.67-2.74 (m, 2H, $\left.\mathrm{CH}_{2}\right) 2.96-3.13\left(\mathrm{~m}, 2 \mathrm{H}, \mathrm{CH}_{2}\right) 4.50(\mathrm{~s}$ (br), $1 \mathrm{H}, \mathrm{NH}) 5.19-5.27(\mathrm{~m}, 1 \mathrm{H}, \mathrm{CH}) 6.18(\mathrm{~d}, J=15.0 \mathrm{~Hz}, 1 \mathrm{H}, \mathrm{CH}) 7.09$ (ddd, $J=15.0,5.0,3.0 \mathrm{~Hz}, 1 \mathrm{H}, \mathrm{CH}) 7.27(\mathrm{~s}, 1 \mathrm{H}, \mathrm{ArH}) 7.54(\mathrm{t}, J=7.5 \mathrm{~Hz}$, $2 \mathrm{H}$, ArH) $7.64(\mathrm{t}, J=7.5 \mathrm{~Hz}, 1 \mathrm{H}, \mathrm{ArH}) 7.83(\mathrm{~d}, J=7.5 \mathrm{~Hz}, 2 \mathrm{H}, \mathrm{ArH}) \mathrm{ppm}$. ${ }^{13} \mathrm{C} \mathrm{NMR}\left(125 \mathrm{MHz}, \mathrm{CDCl}_{3}\right): \delta=14.1\left(\mathrm{CH}_{3}\right) 22.5\left(\mathrm{CH}_{2}\right) 23.0\left(\mathrm{CH}_{2}\right) 25.7$ $\left(\mathrm{CH}_{2}\right) 28.4\left(\mathrm{CH}_{3}\right) 29.0\left(\mathrm{CH}_{2}\right) 29.2\left(\mathrm{CH}_{2}\right) 29.4\left(\mathrm{CH}_{2}\right) 31.5\left(\mathrm{CH}_{2}\right) 33.7\left(\mathrm{CH}_{2}\right)$ $39.9\left(\mathrm{CH}_{2}\right) 60.7(\mathrm{CH}) 79.3(\mathrm{C}) 119.3(\mathrm{CH}) 127.8(\mathrm{CH}) 129.5(\mathrm{CH}) 132.7$ (CH) $133.9(\mathrm{CH}) 139.3$ (C) $142.2(\mathrm{CH}) 149.1$ (C) 156.0 (CO) ppm. HRMS $\left(\mathrm{ES}^{+}\right) \mathrm{C}_{26} \mathrm{H}_{41} \mathrm{~N}_{4} \mathrm{O}_{4} \mathrm{~S}\left(\mathrm{MH}^{+}\right)$calcd. 505.2849; found 505.2834. [a] $]_{\mathrm{D}}=+68(\mathrm{c}$ $=0.1, \mathrm{CH}_{2} \mathrm{Cl}_{2}$ )

Viability assays: the effect of each final compound in the series on parasite growth was determined using the Alamar Blue cell viability assay. This assay was performed in triplicate according to Räz et al ${ }^{[41]}$ Briefly, T. b. brucei cells (strain MIT at 1.1) were seeded in 96-well plates at a density of $2 \times 10^{5}$ cells $/ \mathrm{mL}$ in $100 \mu \mathrm{L}$ media in the presence of varying concentrations of predicted inhibitors $(5 \mu \mathrm{M}, 1 \mu \mathrm{M}, 500 \mathrm{~nm}, 100 \mathrm{nM}, 10$ $\mathrm{nM}, 100 \mathrm{pM}$ ) or DMSO alone. A further $30 \mu \mathrm{L}$ of media was added to each well. After $6 \mathrm{~h}, 15 \mu \mathrm{L}$ of Alamar Blue (Invitrogen) was added to the cells and incubation continued so that the total incubation time was $24 \mathrm{~h}$. Absorbances at 540 and $595 \mathrm{~nm}$ were measured using a SpectraMax M3 Microplate Reader (Molecular Devices), and $\mathrm{EC}_{50}$ values were calculated using the GraphPad Prism 5 software.

Computational methodology: all compounds were initially drawn using Accelrys Draw v4.2 (Biovia, Dassault Systèmes). The series were converted from 2D to 3D using CORINA v3.2 (Molecular Networks $\mathrm{GmbH}$ ) following protonation state prediction via the pka predictor plugin, Marvinview (Chemaxon Ltd.). OMEGA v2.5.1.4 (Openeye Scientific Software) was subsequently used to generate up to 1000 conformers of each compound. The $\mathrm{X}$-ray structure of $\mathrm{T}$. brucei rhodesain in complex with inhibitor K777 (PDB ID: 2P7U) was downloaded from the Protein Data Bank (http://www.rcsb.org). ROCS (Openeye Scientific Software) was used to align all members of the compound series to K777 and ranked by TanimotoCombo. After reinsertion of the covalent adduct with the sulfur of the active site cysteine thiol for all ligands (except 24) optimization of each ligand in the active site of 2P7U using LigX, MOE v2012.10 (Chemical Computing Group) was carried out to refine the structural interactions fixing any initial hydrogen bonds present.

\section{Acknowledgements}

The authors would like to thank Dublin Institute of Technology for financial support (A.K.), University College Dublin for financial support (W.D.) and the Irish Research Council (IRC) for funding through the Enterprise Partnership Scheme (N.A.).

Keywords: Peptidomimetics • Click chemistry • Antiprotozoal agents $\bullet$ Inhibitors $\bullet$ Molecular modelling 
[1] A. R. Renslo, J. H. McKerrow, Nat. Chem. Biol. 2006, 2, 701-710.

[2] Control and Surveillance of Human African Trypanosomiasis; World Health Organization: Geneva 2013

http://apps.who.int/iris/bitstream/10665/95732/1/9789241209847_eng.p df

[3] P. P. Simarro, A. Diarra, J. A. R. Postigo, J. R. Franco, J. G. Jannin, PLoS Negl. Trop. Dis. 2011, 5, e1007.

[4] Human African Trypanosomiasis (Fact Sheet No. 259); World Health Organization 2016,

http://www.who.int/topics/tropical_diseases/factsheets/neglected/en/

[5] http://www.who.int/neglected_diseases/news/HAT_lowest_caseload_ recorded/en/

[6] K. R. Matthews, Science 2011, 331, 1149-1153.

[7] J. D. Barry, R. McCulloch, Adv. Parasitol. 2001, 49, 1-70.

[8] A. H. Fairlamb, Trends Parasitol. 2003, 19, 488-494.

[9] S. A. Thompson, P. R. Andrews, R. P. Hanzlik, J. Med. Chem. 1986, 29, 104-111.

[10] S. Liu, R. P. Hanzlik, J. Med. Chem. 1992, 35, 1067-1075.

[11] I. D. Kerr, J. H. Lee, C. J. Farady, R. Marion, M. Rickert, M. Sajid, K. C. Pandey, C. R. Caffrey, J. Legac, E. Hansell, J. H. McKerrow, C. S. Craik, P. J. Rosenthal, L. S. Brinen, J. Biol. Chem. 2009, 284, 2569725703.

[12] I. D. Kerr, P. Wu, R. Marion-Tsukamaki, Z. B. Mackey, L. S. Brinen, PLoS Negl. Trop. Dis. 2010, 4, e701.

[13] J. T. Palmer, D. Rasnick, J. L. Klaus, D. Brömme, J. Med. Chem. 1995, 38, 3193-3196.

[14] J. Clayton, Nature 2010, 465, S12-S15.

[15] E. Dunny, W. Doherty, P. Evans, J. P. G. Malthouse, D. Nolan, D.; A. J. S. Knox, J. Med. Chem. 2013, 56, 6638-6650.

[16] W. Doherty, J. James, P. Evans, L. Martin, N. Adler, D. Nolan, A. Knox, Org. Biomol. Chem. 2014, 12, 7561-7571.

[17] V. V. Rostovtsev, L. G. Green, V. V. Fokin, K. B. Sharpless, Angew. Chem. Int. Ed. 2002, 41, 2596-2599.

[18] C. W. Tornøe, C. Christensen, M. Meldal, J. Org. Chem. 2002, 67, 3057-3064.

[19] D. J. Craik, D. P. Fairlie, S. Liras, D. Price, Chem. Biol. Drug Des. 2013, 81, 136-147.

[20] E. Ko, L. M. Perez, G. Lu, A. Schaefer, K. Burgess, J. Am. Chem. Soc. 2011, 133, 462-477.

[21] D. S. Pedersen, A. Abell, Eur. J. Org. Chem. 2011, 2399-2411.

[22] I. E. Valverde, A. Bauman, C. A. Kluba, S. Vomstein, M. A. Walter, T. L. Mindt, Angew. Chem. Int. Ed. 2013, 52, 8957-8960.

[23] K. Brak, P. S. Doyle, J. H. McKerrow, J. A. Ellman, J. Am. Chem. Soc. 2008, 130, 6404-6410.
[24] W. Doherty, P. Evans, J. Org. Chem. 2016, 81, 1416-1424.

[25] B.-Y. Lee, S. R. Park, H. B. Jeon, K. S. Kim, Tetrahedron Lett. 2006, 47, 5105-5109.

[26] L. Zhang, Y. Zhang, J. Dong, J. Liu, L. Zhang, H. Sun, Bioorg. Med. Chem. Lett. 2012, 22, 1036-1039.

[27] F. M. Cordero, P. Bonanno, M. Chioccioi, P. Gratteri, I. Robina, A. J. M. Vargas, A. Brandi, Tetrahedron 2011, 67, 9555-9564.

[28] S. Ziegler, V. Pries, C. Hedberg, H. Waldmann, Angew. Chem. Int. Ed. 2013, 52, 2744-2792

[29] H. Johansson, D. S. Pedersen, Eur. J. Org. Chem. 2012, 4267-4281.

[30] A. Ito, R. Takahashi, Y. Baba, Chem. Pharm. Bull. 1975, 23, 3081-3087.

[31] S. Müller, B. Liepold, G. J. Roth, H. J. Bestmann, Synlett 1996, 521-522.

[32] A standard Ohira-Bestmann reaction was carried out on a diastereomerically pure dipeptide aldehyde (reference 15). This confirmed that racemization/epimerisation is a general feature for this type of Ohira-Bestmann protocol. See supporting information for experimental details.

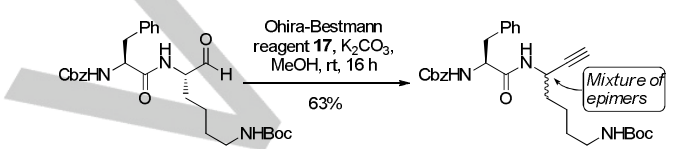

[33] S. Manaviazar. K. J. Hale, A. LeFranc, Tetrahedron Lett. 2011, 52, 2080-2084.

[34] L. Fantetti, G. Adembri, A. Giotti, I. Masini, G. Roncucci, Arzneim.Forsch./Drug Res. 1999, 49, 137-143.

[35] E. D. Goddard-Borger, R. V. Stick, Org. Lett. 2007, 9, 3797-3800.

[36] P. Loos, C. Ronco, M. Riedrich, H.-D. Arndt, Eur. J. Org. Chem. 2013, 3290-3315.

[37] D. E. O'Connor, W. I. Lyness, J. Am. Chem. Soc. 1964, 86, 3840-3846.

[38] G. Wang, U. Mahesh, G. Y. J. Chen, S. Q. Yao, Org. Lett. 2003, 5, 737740.

[39] P. T. Ho, K. Ngu, J. Org. Chem. 1993, 58, 2313-2316.

[40] J. T. Lee, D. Y. Chen, Z. Yang, A. D. Ramos, J. J.-D. Hsieh, M. Bogyo, Bioorg. Med. Chem. Lett. 2009, 19, 5086-5090.

[41] B. Räz, M. Iten, Y. Grether-Bühler, R. Kaminsky, R. Brun, Acta Trop. 1997, 68, 139-147.

[42] M. G. Götz, C. R. Caffrey, E. Hansell, J. H. McKerrow, J. C. Powers, Bioorg. Med. Chem. 2004, 12, 5203-5211. 
Entry for the Table of Contents (Please choose one layout)

Layout 2:

FULL PAPER

Key Topic* Peptidomimetics

William Doherty, Nikoletta Adler, Andrew Knox, Derek Nolan, Joanna McGouran,

Anna Pratima Nikalje, Aniket Sarkate,

Deepak Lokwani, and Paul Evans

Approaches are described to access 1,2,3-triazole-derived peptidyl vinyl sulfone

Page No. - Page No.

Trypanosoma brucei brucei inhibitors via click chemistry from common azide precursors. Among the triazole analogues, 7-12, are biotinylated inhibitors which offer possibilities as cysteine protease probes. Further to this, two syntheses of a 1,2,3-triazole based vinyl sulfone $\mathbf{5}$ and its allylic isomer $\mathbf{2 4}$ are presented.

Synthesis and Evaluation of 1,2,3Triazole-Containing Vinyl and Allyl Sulfones as Anti-Trypanosomal Agents
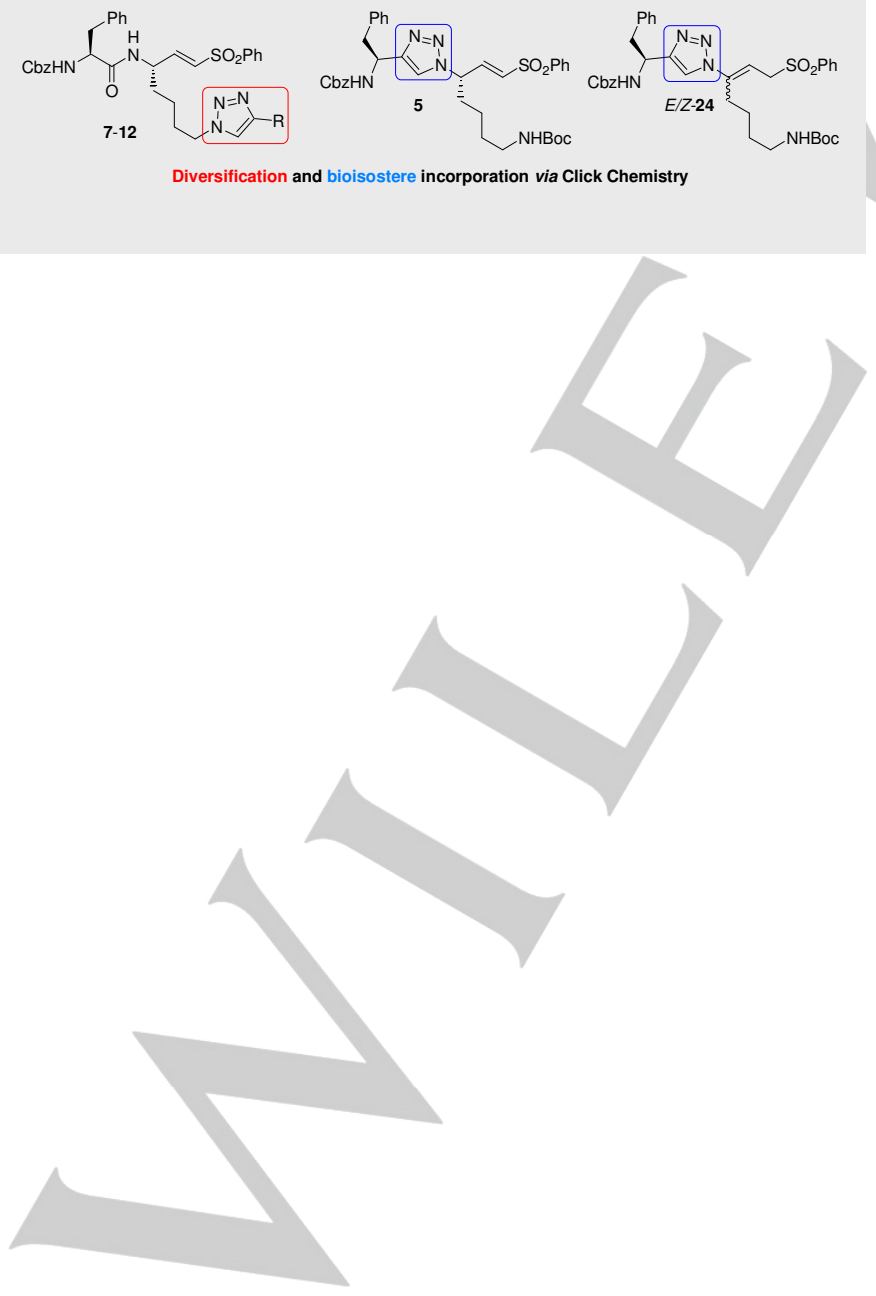